\title{
Identification of Amino Acid Residues in GluR1 Responsible for Ligand Binding and Desensitization
}

\author{
T. G. Banke, ${ }^{3}$ J. R. Greenwood, ${ }^{2}$ J. K. Christensen, ${ }^{1}$ T. Liljefors, ${ }^{2}$ S. F. Traynelis, ${ }^{3}$ A. Schousboe, ${ }^{1}$ and \\ Darryl S. Pickering ${ }^{1}$
}

Departments of ${ }^{1}$ Pharmacology and ${ }^{2}$ Medicinal Chemistry, NeuroScience PharmaBiotech Research Center, The Royal Danish School of Pharmacy, DK-2100 Copenhagen, Denmark, and ${ }^{3}$ Department of Pharmacology, Emory University, Atlanta, Georgia 30322

\begin{abstract}
Although GluR1。 and GluR3, are homologous at the amino acid level, GluR3, desensitizes approximately threefold faster than GluR1 $1_{0}$. By creating chimeras of GluR1。 and GluR3。 and point amino acid exchanges in their $\mathrm{S} 2$ regions, two residues were identified to be critical for GluR1。 desensitization: Y716 and the R/G RNA-edited site, R757. With creation of the double-point mutant (Y716F, R757G)GluR1。, complete exchange of the desensitization rate of GluR1。 to that of GluR3 o was obtained. In addition, both the potency and affinity of the subtype-selective agonist bromohomoibotenic acid were exchanged by the
\end{abstract}

Y716F mutation. A model is proposed of the AMPA receptor binding site whereby a hydrogen-bonding matrix of water molecules plays an important role in determining both ligand affinity and receptor desensitization properties. Residues Y716 in GluR1 and F728 in GluR3 differentially interact with this matrix to affect the binding affinity of some ligands, providing the possibility of developing subtype-selective compounds.

Key words: AMPA receptor; desensitization; binding site; GluR1; GluR2; GluR3; GluR4 agonist subtype-selectivity; mutant receptors
L-glutamate, the major excitatory neurotransmitter in the brain, activates three distinct types of ionotropic glutamate receptors (iGluR): NMDA receptors, AMPA receptors (AMPARs), and kainate (KA) receptors (for review, see Hollmann and Heinemann, 1994; Dingledine et al., 1999). These receptor channels consist of a heteromeric complex composed of four or five subunits (Ferrer-Montiel and Montal, 1996; Mano and Teichberg, 1998; Rosenmund et al., 1998). Four different subunits (GluR1-4) can contribute to the formation of AMPARs and are capable of forming functional homomeric and heteromeric channels (Brose et al., 1994). GluR1-4 can exist in two alternate splice versions, termed flip and flop (Sommer et al., 1990), which show differences in their desensitization properties (Mosbacher et al., 1994; Koike et al., 2000) and their sensitivity to blockers of desensitization, such as cyclothiazide (Partin et al., 1994). In addition, in GluR2, GluR3, and GluR4, intronic elements determine a codon switch in the primary transcripts at a position termed the $R / G$ site that immediately precedes the flip/flop region (Lomeli et al., 1994). The $\mathrm{R} / \mathrm{G}$ site also affects receptor desensitization properties as well as recovery from desensitization.

Native and cloned AMPARs desensitize rapidly and almost completely in response to glutamate application, on a millisecond time scale (Mayer and Westbrook, 1987; Stern-Bach et al., 1998; Dingledine et al., 1999). Excessive activation of iGluRs, for example by blocking their desensitization, may mediate neuronal

Received Dec. 15, 2000; revised Jan. 23, 2001; accepted Jan. 30, 2001.

This work was supported by Grants 9700761, 9900010, and 9900201 from the Danish Medical Research Council, by the Lundbeck, Alfred Benzon, and Novo Nordisk Foundations, and by the National Institutes of Health, National Institute of Neurological Disorders and Stroke. We thank Dr. D. Bowie for discussions and critical reading of the manuscript. We also thank Dr. Ulf Madsen for generously supplying us with $(R, S)$-4-bromohomoibotenic acid.

Correspondence should be addressed to Dr. Darryl S. Pickering, Department of Pharmacology, The Royal Danish School of Pharmacy, 2 Universitetsparken, DK2100 Copenhagen, Denmark. E-mail: picker@dfh.dk.

Copyright (C) 2001 Society for Neuroscience $0270-6474 / 01 / 213052-11 \$ 15.00 / 0$ excitotoxic death (Jensen et al., 1998, 1999). Consequently, iGluRs are thought to play a role in several neurological disorders and neurodegenerative diseases (Bittigau and Ikonomidou, 1997). However, although there is substantial knowledge relating to iGluR desensitization at the cellular level, relatively little is known about the molecular mechanism of desensitization. In contrast, the characterization of the agonist binding domain of iGluRs has been greatly advanced by x-ray crystal structure data of soluble GluR2 binding domain constructs consisting of segments S1 and S2 joined together by a polypeptide linker (Armstrong et al., 1998; Armstrong and Gouaux, 2000). S1 is located $\mathrm{N}$-terminal to transmembrane domain I (TMD I), whereas S2 is situated between TMD III and TMD IV and contains the flip/flop and R/G sites. Agonist binding to AMPARs is thought to involve an interaction of S1 with S2 that yields a closed configuration, which has been suggested to be related to both efficacy and desensitization (Paas, 1998; Armstrong and Gouaux, 2000; Krupp and Westbrook, 2000).

In the present study, AMPAR amino acid residues involved in both ligand binding and channel gating were investigated by creating receptor chimeras and point exchanges between two homologous AMPAR subunits, GluR1 $1_{\mathrm{o}}$ and GluR3 $3_{\mathrm{o}}$. Because GluR3 $_{\mathrm{o}}$ has a faster desensitization rate constant than GluR $1_{\mathrm{o}}$, it was possible to investigate the molecular reasons for this difference. In addition, although the homology in the S1 and S2 regions between these subunits is 81 and $92 \%$, respectively, they are not identical. Our recent discovery (Coquelle et al., 2000) of an AMPAR subtype-selective agonist, $(S)$-4-bromohomoibotenic acid $[(S)$-BrHIBO], made it possible to investigate differences in the binding sites of GluR $1_{o}$ versus GluR $3_{\mathrm{o}}$ responsible for determining this selectivity.

\section{MATERIALS AND METHODS}

Mutagenesis. For preparation of high-expression cRNA transcripts, GluR $1_{\mathrm{o}}$ and GluR3 $3_{\mathrm{o}}$ (provided by Dr. S. F. Heinemann, The Salk 


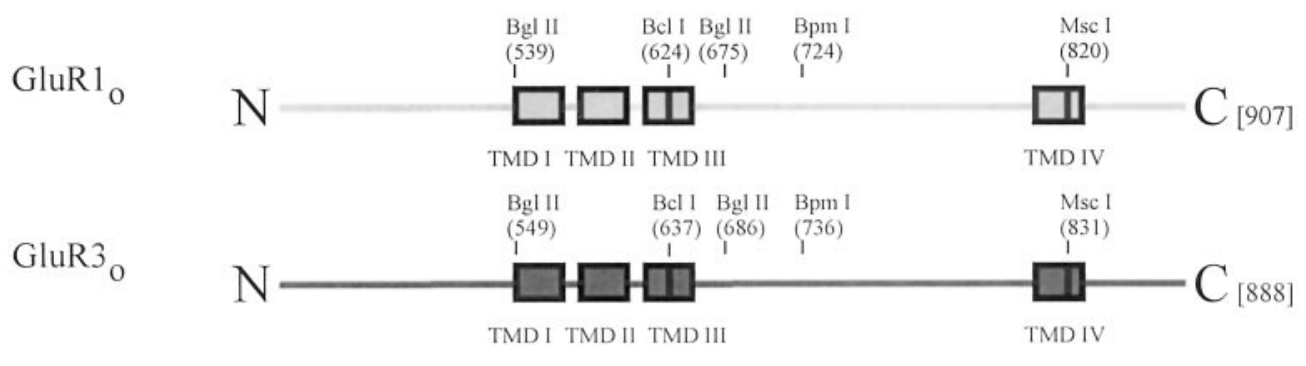

Chimera 1

(NG1-CG3)
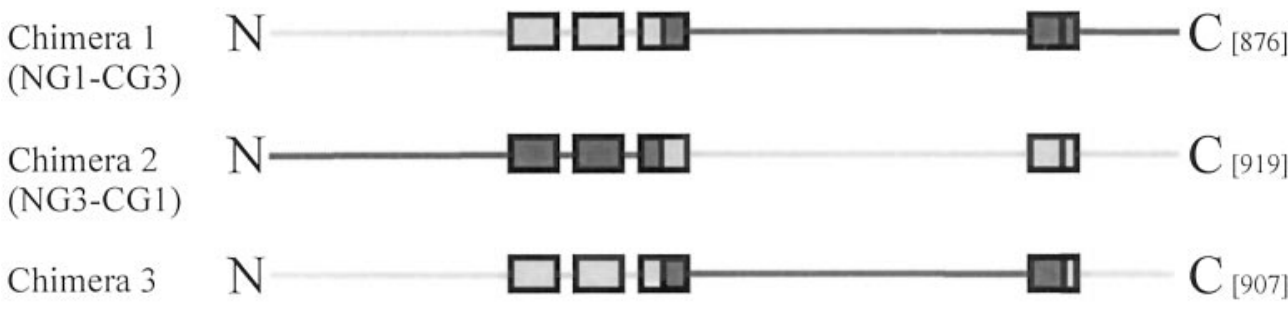

-

ㅁ]

$C_{[907]}$

Chimera 4
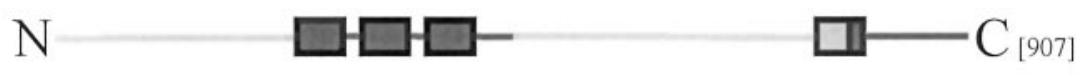

Chimera 5
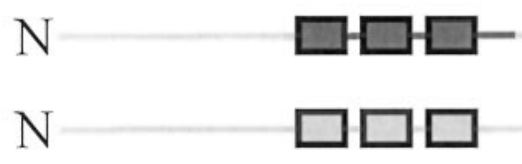

ㅁ]

$\mathrm{C}_{[909]}$

Chimera 6

$$
\mathrm{N}
$$
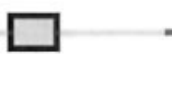

Chimera 7

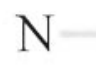

$\square \square \square$

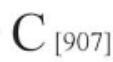

C [907]
Figure 1. Chimeric constructs of GluR $1_{o}$ and GluR3 $3_{\mathrm{o}}$. The GluR1 $1_{\mathrm{o}}$ sequence is represented by light gray areas, and the GluR $3_{\mathrm{o}}$ sequence is represented by black areas. Numbering above the wild-type sequences refers to amino acid position number, starting from the initiation methionine. The corresponding restriction enzyme sites in the cDNA used to create these constructs are also indicated. The amino acid length of each protein is given in square brackets. Note that chimeras 1 and 2 were previously named NG1-CG3 and NG3-CG1, respectively (Banke et al., 1997), but have been renamed here for simplicity. TMD I through TMD IV are indicated as boxes; $N$, $\mathrm{N}$ terminus; $C, \mathrm{C}$ terminus. This figure is not drawn to scale.
Institute, La Jolla, CA) were each inserted into the pGEM HE vector (Liman et al., 1992) at the (5')-Bam HI and (3')-XbaI sites of the multiple cloning site. All of the $5^{\prime}$ and $3^{\prime}$ untranslated sequence had been removed from these clones. GluR $4 \mathrm{c}_{\mathrm{o}}$ in pBluescript SK $(-)$ vector (kindly supplied by Dr. A. Buonanno, National Institutes of Health, Bethesda, MD) was digested with $X h o I$, treated with Klenow enzyme to produce blunt ends, and subsequently digested with $B a m H I$. The GluR $4 c_{o}$ insert was then subcloned into the (5')-BamHI and (3')-XbaI (blunt-ended with Klenow enzyme) sites of pGEM HE vector, leaving a $58 \mathrm{bp} 5^{\prime}$ - and $\approx 430 \mathrm{bp}$ $3^{\prime}$-untranslated sequence. Mutagenesis was performed with the QuikChange site-directed mutagenesis kit (Stratagene, La Jolla, CA) using the GluR $1_{\mathrm{o}}$, GluR $3_{\mathrm{o}}$, or GluR4c $\mathrm{c}_{\mathrm{o}}$ pGEM HE cDNA as a template. Mutagenic oligonucleotides were obtained from DNA Technology A/S (Aarhus, Denmark) and also contained silent restriction sites for screening of mutant colonies. Mutated regions were cassetted back into the corresponding template cDNA and then sequenced-verified using the BigDye Terminator Cycle Sequencing Kit and an Applied Biosystems Prism 310 Sequencer (Perkin-Elmer, Foster City, CA). cDNAs were grown in XL1 Blues bacteria (Stratagene) and prepared using column purification (Qiagen, Chatsworth, CA). cRNA was synthesized from these cDNAs using the mMessage mMachine T7 mRNA-capping transcription kit (Ambion, Austin, TX).

Creation of chimeric receptors. Chimeric GluR $1_{\mathrm{o}}-\mathrm{GluR} 3_{\mathrm{o}}$ receptors were created using naturally occurring restriction enzyme sites in the wild-type receptor cDNAs (Fig. 1). Construction of chimeras 1 and 2 has been described previously (Banke et al., 1997); these chimeras were formerly named NG1-CG3 and NG3-CG1, respectively.

Recombinant baculovirus construction. The baculovirus-Sf9 cell system was used to express recombinant AMPAR complexes used for radioligand binding assays. All manipulations of virus and insect cells, including maintenance of cell culture, transfection, plaque purification, amplification, and expression of receptor, were according to standard protocols in the Guide to Baculovirus Expression Vector Systems and Insect Cell Culture Techniques (Life Technologies, Paisley, UK) and Baculovirus Expression Vector System: Procedures and Methods Manual, Second Edition (PharMingen, San Diego, CA). The creation and expression of recombinant GluR $1_{\text {o }}$ and GluR3 3 baculoviruses and Sf9 cell culture have been described previously (Nielsen et al., 1998). Baculoviruses of the mutants
(Y716F, R757G)GluR1 $1_{\mathrm{o}}$, (Y716F)GluR1 $1_{\mathrm{o}}$, (F728Y, G769R)GluR3 ${ }_{\mathrm{o}}$, and (F728Y)GluR3 3 were made in the same manner by subcloning these mutants from the pGEM HE vector into a baculovirus transfer vector and using the PharMingen BaculoGold transfection kit.

Radioligand binding. The affinities of compounds at wild-type and mutant receptors were determined from competition experiments with $(R, S)$-[5-methyl- $\left.{ }^{3} \mathrm{H}\right] \mathrm{AMPA}(40.87 \mathrm{Ci} / \mathrm{mmol}$; NEN, Boston, MA) as described previously (Nielsen et al., 1998; Coquelle et al., 2000). Competition data were fit to a logistic equation (Eq. 1) to determine the Hill coefficient $\left(n_{\mathrm{H}}\right)$ or to Equation 2 for calculation of the drug affinity $\left(K_{\mathrm{i}}\right)$ :

$$
\begin{gathered}
T B_{\max } /\left(1+\left([I] / \mathrm{IC}_{50}\right)^{n \mathrm{H}}\right)+\mathrm{NSB} \\
\left(R_{\mathrm{t}} \cdot L_{\mathrm{t}} / K_{\mathrm{d}}\right) /\left(1+L_{\mathrm{t}} / K_{\mathrm{d}}+[I] / K_{\mathrm{i}}\right)+\mathrm{NSB},
\end{gathered}
$$

where $K_{\mathrm{d}}$ equals radioligand dissociation constant, $K_{\mathrm{i}}$ equals inhibitor dissociation constant, $L_{\mathrm{t}}$ equals total radioligand concentration, $T B_{\max }$ equals total radioligand bound at zero competitor concentration, $n_{\mathrm{H}}$ equals Hill coefficient, NSB equals nonspecific binding, and $[I]$ equals total competitive inhibitor concentration.

Oocyte preparation. Mature female Xenopus laevis (African Reptile Park, Tokai, South Africa) were anesthetized using $0.1 \%$ ethyl 3 -aminobenzoate, and ovaries were surgically removed. The ovarian tissue was dissected and treated with $2 \mathrm{mg} / \mathrm{ml}$ collagenase in $\mathrm{Ca}^{2+}$-free Barth's medium for $2 \mathrm{hr}$ at room temperature and subsequently defolliculated using fine forceps. On the second day, oocytes were injected with 50-100 $\mathrm{nl}$ of $\sim 1 \mu \mathrm{g} / \mu \mathrm{l} \mathrm{cRNA}$ and incubated in Barth's medium (in mM): $88 \mathrm{NaCl}, 1 \mathrm{KCl}, 0.33 \mathrm{Ca}\left(\mathrm{NO}_{3}\right)_{2}, 0.41 \mathrm{CaCl}_{2}, 0.82 \mathrm{MgSO}_{4}, 2.4$ $\mathrm{NaHCO}_{3}$, and $10 \mathrm{HEPES}, \mathrm{pH} 7.4$, with gentamicin $(0.10 \mathrm{mg} / \mathrm{ml})$ at $17^{\circ} \mathrm{C}$. Oocytes were used for recordings from 6 to $10 \mathrm{~d}$ after injection.

Two-electrode voltage clamp. The oocytes were voltage-clamped by using a two-electrode voltage clamp (Dagan Corporation, Minneapolis, $\mathrm{MN}$ ) having a virtual ground, with both microelectrodes filled with $3 \mathrm{M}$ $\mathrm{KCl}$. Recordings were made while the oocytes were continuously superfused with frog Ringer's solution (in $\mathrm{mM}$ ): $115 \mathrm{NaCl}, 2 \mathrm{KCl}, 1.8 \mathrm{CaCl}_{2}$, and 5 HEPES, pH 7.0. Drugs were dissolved in Ringer's solution and were added by bath application. All recordings were made at room temperature at a holding potential $\left(\mathrm{V}_{\mathrm{h}}\right)$ of $-80 \mathrm{mV}$. In our hands, oocyte 
calcium-activated chloride channels have never been observed to interfere with the expressed AMPAR currents.

Agonist concentration-response curves were constructed by measuring the maximal current induced by increasing concentrations of agonist. Data from individual oocytes were fit to a logistic equation: $I=I_{\max } /[1$ $\left.+\left(\mathrm{EC}_{50} /[\text { agonist }]\right)^{n} \mathrm{H}\right]$, where $I$ is the response observed at a given agonist concentration. The parameters $I_{\max }$ (maximal current observed at infinite agonist concentration), $n_{\mathrm{H}}$ (Hill coefficient), and the $\mathrm{EC}_{50}$ were determined by an iterative least squares fitting routine.

Patch-clamp recordings. Injected oocytes were prescreened with a twoelectrode voltage clamp; those having a response $>200 \mathrm{nA}\left(V_{\mathrm{h}}=-80\right.$ $\mathrm{mV}$ ) to $300 \mu \mathrm{M} \mathrm{KA}$ were selected for further investigation. The vitelline membrane was removed by placing the oocyte in a $35 \mathrm{~mm}$ dish containing a hyperosmotic medium (in $\mathrm{mM}$ ): $200 \mathrm{~K}^{+}$-aspartate, $20 \mathrm{KCl}, 1 \mathrm{MgCl}_{2}, 5$ EGTA-KOH, and 10 HEPES-KOH, pH 7.4. After 10-15 min in this solution, the vitelline membrane was removed with a pair of fine forceps. Outside-out patches from oocytes were prepared with thin-walled glass capillaries (World Precision Instruments, Sarasota, FL) filled with (in $\mathrm{mM}$ ): $100 \mathrm{KCl}, 10 \mathrm{EGTA}$, and 10 HEPES, $\mathrm{pH}$ 7.0. Pipettes had a resistance of 3-5 M $\Omega$. The external solution was frog Ringer's. Fast application of agonists to outside-out membrane patches was made using a double-barreled theta-glass tube (outer diameter, $2.0 \mathrm{~mm}$; wall thickness, $0.3 \mathrm{~mm}$; septum thickness, $0.12 \mathrm{~mm}$; Hilgenberg, Malsfeld, Germany). Frog Ringer's solution flowed continuously through one barrel, while the other barrel contained either $10 \mathrm{~mm}$ L-glutamate or $1 \mathrm{~mm}$ $(R, S)$-BrHIBO. The theta-glass tube was stepped using a piezo-electric element (Burleigh Instruments, Fishers, NY). By measuring the change in junction current between two different buffer solutions, the 10-90\% rise time was determined to be $<100 \mu$ sec. Rate constants ( $\tau$ values) were determined by fitting the average macroscopic responses to the following rate equation: $A_{\mathrm{t}}=A_{\mathrm{o}} \mathrm{e}^{-\mathrm{t} / \tau}+I_{\mathrm{ss}}$, where $A_{\mathrm{t}}$ is the current amplitude at time (t), $A_{\mathrm{o}}$ is the maximum current amplitude, e is the base of the natural logarithm, $I_{\mathrm{ss}}$ is the steady-state current, and $\tau$ is the rate constant. Currents were recorded with an RK-400 amplifier (Bio-Logic Science Instruments, Claix, France), filtered at $2 \mathrm{kHz}$, and digitized with a sampling rate of $20 \mathrm{kHz}$; data were stored on-line onto a personal computer hard disk drive.

Sequence and data analyses software. Nucleotide and protein alignments and sequence comparisons were performed using PCgene version 6.60 (IntelliGenetics Inc., Mountain View, CA). The GluR $1_{\mathrm{o}}$, GluR $3_{\mathrm{o}}$, and GluR $4 c_{o}$ proteins are numbered here beginning from the initiation methionine. The numbering for GluR2 is as given in Armstrong et al. (1998). Unless otherwise stated, one-way ANOVA (followed by the Bonferroni $t$ test, if required) or Student's $t$ test was used for comparison of the parameters of the receptors using SigmaStat for Windows version 2.0 (SPSS Science, Chicago, IL) or GraphPad (San Diego, CA) Instat version 2.01. Values were considered statistically significantly different if $p$ values were $<0.05$. Electrophysiological data were analyzed as described above using NPM (written by Dr. Steve Traynelis, Emory University, Atlanta, GA), VClamp version 6.0 (Cambridge Electronic Design, Cambridge, UK), and Origin version 5.0 (Microcal Software, Northampton, MA); binding data were analyzed using Grafit version 3.00 (Erithacus Software Ltd., Horley, UK).

Molecular modeling. The amino acid sequences of GluR1-4 (flop versions) were aligned with the GluR2-S1S2I construct described by Armstrong et al. (1998) using Macaw software version 2.0.5 (http:// www.ncbi.nlm.nih.gov) (Schuler et al., 1991; Lawrence et al., 1993). Models of the binding sites of GluR1-4 were built from GluR2-S1S2J complexed with various ligands (Armstrong et al., 2000) by interchanging homologous amino acids, in particular Y702 (GluR2) for phenylalanine in GluR3 and GluR4. This was justified on the basis of previous models of GluR1-4 homology built from GluR2-S1S2I using Swiss-Model via the Expert Protein Analysis System (ExPASy) Molecular Biology Server (Swiss Institute of Bioinformatics, Geneva, Switzerland; http://www.expasy.ch), which showed very little deviation of backbone and side chains around the binding site.

Based on the crystal structures of GluR2-S1S2J complexed with L-glutamate and (S)-AMPA (Armstrong et al., 2000), models were constructed of these ligands as well as for $(S)$-BrHIBO bound to GluR1 and GluR3. A reasonable binding conformation for the tri-ionized form of $(S)$-BrHIBO was found by a Monte Carlo search of the conformational space according to the MMFF94 forcefield in MacroModel version 6.5 (Mohamadi et al., 1990) including the GB/SA solvation model. The chosen local minimum energy conformation lay $0.05 \mathrm{kcal} / \mathrm{mol}$ above the global minimum. The binding positions of $(S)$-BrHIBO were estimated by overlaying the formally charged atoms of $(S)$-BrHIBO on $(S)$ AMPA. The two $\alpha$-amino acid portions were matched directly, but the isoxazole ring of $(S)$-BrHIBO was inverted around the carboxylate bioisostere, matching the ring $\mathrm{N}$ with $\mathrm{O} 1$ and vice versa, as suggested previously (Christensen et al., 1992; Greenwood et al., 1998).

Calculations were performed to confirm the preferred sites for water molecules within the ligand-binding cavities of the agonist-bound state of the GluR1 and GluR3 homology models using the program GRID, version 18 (Goodford, 1985). The proton positions and hydrogenbonding networks were established by a combination of inspection, energy minimization, and Monte Carlo methods to resolve ambiguities as follows: all waters and side-chain hydroxyls within $8.5 \AA$ of the ligand were rotated randomly to give thousands of initial structures. The positions of the protons were then optimized, including all atoms within a $12.5 \AA$ radius, again using the MMFF94 forcefield (Mohamadi et al., 1990). (For additional details concerning our homology models, interested readers may contact Prof. Tommy Liljefors at the following e-mail address: tl@dfh.dk.)

Finally, simplified models of both HIBO-type and AMPA-type binding relative to the nonconserved Y716(GluR1)/F728(GluR3) residue were constructed, consisting of a benzene or phenol ring representing this residue (TYR or PHE), a deprotonated 3-hydroxy-4,5-dimethylisoxazol anion representing either AMPA (I) or 4-methylhomoibotenic acid (MeHIBO), and two interposing water molecules corresponding to W1 and W3. Fixing as few internal geometric coordinates as possible to retain approximate relative orientations, the four models (I-TYR, I-PHE, II-TYR, and II-PHE) were submitted to quantum mechanical energy minimizations using ab initio B3LYP density functional theory with the $6-31+\mathrm{G}(\mathrm{d})$ basis set in Gaussian 98 version A.7 (Gaussian Inc., Pittsburgh, PA).

Materials. Restriction enzymes and other molecular biological enzymes were obtained from New England BioLabs (Beverly, MA). $(R, S)$-AMPA and $(R, S)$-BrHIBO were synthesized in the Department of Medicinal Chemistry, The Royal Danish School of Pharmacy (Krogsgaard-Larsen et al., 1980; Hansen et al., 1989). Sf900-II culture medium, gentamicin, antibiotics, and plaque assay reagents were obtained from Life Technologies. KA and L-quisqualic acid were purchased from Tocris Cookson Ltd. (Bristol, UK). Collagenase and additional chemicals and reagents were obtained from Sigma (St. Louis, MO) or similar local suppliers.

\section{RESULTS}

\section{Desensitization of wild-type and chimeric AMPARs}

The gating properties of the wild-type, homomeric AMPAR subunits were characterized in $X$. laevis oocytes injected with wild-type GluR1 $1_{\mathrm{o}}$ or GluR3 $3_{\mathrm{o}}$ cRNA. Because the observed desensitization rate constant $(\tau)$ can be dependent on agonist concentration, a high concentration of L-glutamate was used such that $\tau$ was independent of agonist concentration (Koike et al., 2000). Responses of GluR $1_{\mathrm{o}}$ and GluR $3_{\mathrm{o}}$ to fast application $(<100 \mu \mathrm{sec})$ of either 10 mM L-glutamate (Fig. $2 A$ ) or 1 mM BrHIBO (Fig. $2 B$ ) were examined. GluR $1_{\mathrm{o}}$ exhibited a slower desensitization rate compared with GluR3 ${ }_{\mathrm{o}}$ for both agonists, whereas no difference was seen between these agonists. However, the $10-90 \%$ rise time for $1 \mathrm{~mm}(R, S)$-BrHIBO at GluR1 $1_{\mathrm{o}}(826 \pm 24 \mu \mathrm{sec} ; n=5)$ was statistically significantly different from that at GluR $3_{\mathrm{o}}(590 \pm 82$ $\mu$ sec; $n=5)$, and $(R, S)$-BrHIBO showed a significantly slower $10-90 \%$ rise time than that observed with $10 \mathrm{~mm}$ L-glutamate (343 $\pm 39 \mu \mathrm{sec}$ for the 10 fastest patches of GluR $1_{\mathrm{o}}$ ). This difference in rise time could be because $1 \mathrm{~mm}$ BrHIBO is not a saturating concentration of agonist, whereas $10 \mathrm{~mm}$ L-glutamate represents $\sim 20$-fold $\mathrm{EC}_{50}$ (Dingledine et al., 1999).

To localize the region or regions of GluR $1_{\mathrm{o}}$ and GluR3 responsible for determining $\tau$, chimeric $(\mathrm{Ch})$ GluR $1_{\mathrm{o}}-\mathrm{GluR} 3_{\mathrm{o}}$ receptors were created, and their desensitization properties were measured (Figs. 1, 3). All of the tested receptors were functionally expressed in oocytes and showed almost complete desensitization to $10 \mathrm{~mm}$ L-glutamate (Table 1). Chimeras 6 and 7 had $\tau$ values that were not statistically significantly different from one another but that were, however, intermediate between the values 


\section{GluR1 _ GluR3}

A

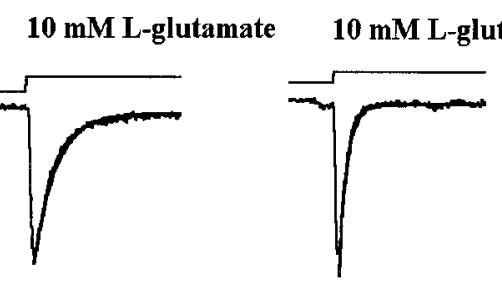

B
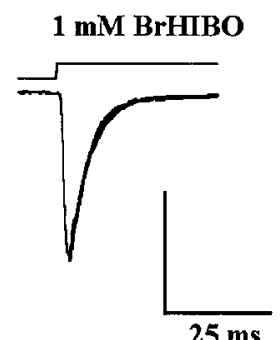

$25 \mathrm{~ms}$

C

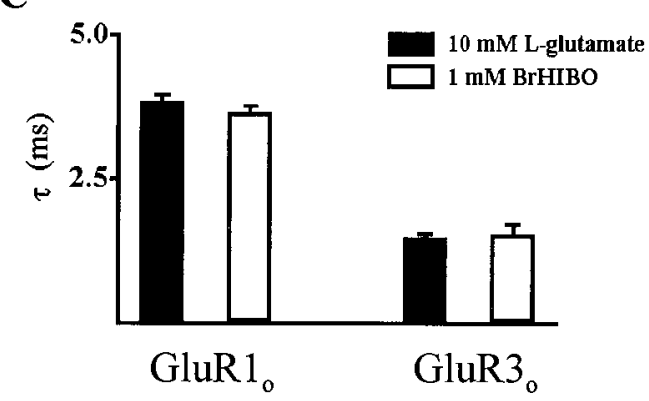

Figure 2. L-glutamate and $(R, S)$-BrHIBO desensitization at GluR $1_{\mathrm{o}}$ and GluR $3_{\mathrm{o}}$. $A$, Comparison of representative currents evoked by $10 \mathrm{~mm}$ L-glutamate on outside-out patches expressing GluR1 $1_{\mathrm{o}}$ (left , scale bar = $40 \mathrm{pA}$ ) or GluR3 ${ }_{\mathrm{o}}$ (right, scale bar $=60 \mathrm{pA}$ ), respectively. L-glutamate was applied by fast application on outside-out patches as shown above the traces $\left(V_{\mathrm{h}}=-60 \mathrm{mV}\right)$. Each trace was fitted to a monoexponential equation (line over traces), and $\tau$ was determined; $\tau\left(\mathrm{GluR} 1_{\mathrm{o}}\right.$ ), $4.2 \mathrm{msec} ; \tau$ (GluR $3_{\mathrm{o}}$ ), 1.5 msec. $B$, Current evoked by $1 \mathrm{~mm}(R, S)$-BrHIBO on outside-out patches expressing GluR1 $1_{\mathrm{o}}$ (left, scale bar $=250 \mathrm{pA}$ ) or GluR3 $_{\mathrm{o}}$ (right, scale bar $\left.=50 \mathrm{pA}\right) ; \tau\left(\right.$ GluR $\left.1_{\mathrm{o}}\right), 4.0 \mathrm{msec} ; \tau\left(\right.$ GluR3$\left._{\mathrm{o}}\right), 1.8$ msec. $C$, Mean $\tau \pm$ SEM for GluR $1_{\mathrm{o}}$ (two left bars) and GluR3 $3_{\mathrm{o}}$ (two right bars). Filled bars, $10 \mathrm{~mm}$ L-glutamate (left, $n=13$; right, $n=16)$; open bars, $1 \mathrm{~mm}(R, S)$-BrHIBO (left, right, $n=5)$.

for GluR $1_{\mathrm{o}}$ and GluR $3_{\mathrm{o}}$. This suggested that there was an amino acid residue or residues in both the $\mathrm{N}$ - and $\mathrm{C}$-terminal halves of the $\mathrm{S} 2$ region that was responsible for determining $\tau$.

\section{Desensitization of AMPAR point mutants}

Alignment of the $\mathrm{S} 2$ regions of GluR $1_{\mathrm{o}}$ and GluR3 ${ }_{\mathrm{o}}$ (Fig. 4A) reveals 15 amino acid differences. Therefore, all these residues in GluR $1_{\mathrm{o}}$ were individually changed to the corresponding GluR3 residue, and $\tau$ was measured (Fig. $4 B$, Table 1 ). All mutants were functional when expressed in oocytes. For three mutants (Y714F, Y716F, and $\mathrm{R} 757 \mathrm{G}$ ), a decreased $\tau$ was observed compared with GluR $1_{\mathrm{o}}$ but full conversion to the rapid GluR3 $3_{\mathrm{o}}$ desensitization rate was not obtained. Residue $\mathrm{R} 757$ of GluR $1_{\mathrm{o}}$ corresponds to the $\mathrm{R} / \mathrm{G}$ editing site and is known to affect desensitization, as well as the recovery from desensitization, after brief application of
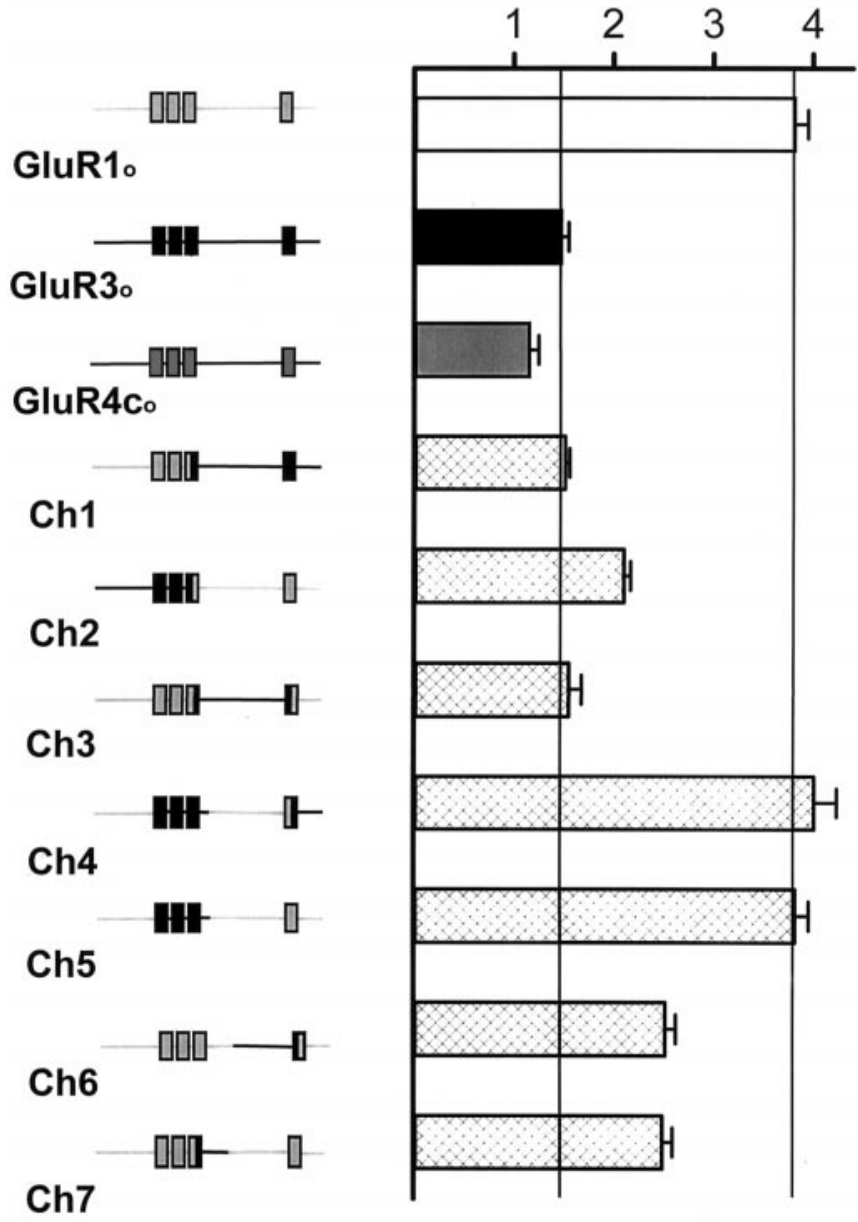

Figure 3. Desensitization at chimeric AMPARs. Comparison of $10 \mathrm{~mm}$ L-glutamate-evoked currents (mean \pm SEM) from, starting at top left, GluR $1_{\mathrm{o}}$, GluR3 $3_{\mathrm{o}}$, GluR4 $\mathrm{c}_{\mathrm{o}}$, and chimeric receptors $(C h)$ 1-7 expressed in $X$. laevis oocytes. The chimeric constructs are shown on the left, as described in Figure 1. L-glutamate was applied by fast application on outside-out patches $\left(V_{\mathrm{h}}=-60 \mathrm{mV}\right)$. Data were fit to a monoexponential equation (see Materials and Methods), and $\tau$ was determined.

agonist to AMPARs (Lomeli et al., 1994). Because R757 is located within the $\mathrm{C}$-terminal half of the $\mathrm{S} 2$ region (Ch6) and Y714 and Y716 are contained within the N-terminal half ( $\mathrm{Ch} 7)$, this explains why each chimera only showed a partial effect on $\tau$. It was decided to construct multiple-point mutations of these residues to obtain a full conversion of GluR $1_{\mathrm{o}} \tau$ to that of GluR3 .

\section{Desensitization, recovery, and deactivation of AMPAR mutants}

For the double-point mutant (Y714F, Y716F)GluR1 $1_{\mathrm{o}}, \tau$ was statistically significantly different from that for $\mathrm{GluR}_{\mathrm{o}}$ and for GluR3 (Fig. 4B, Table 1). The double-point mutant (Y714F, R757G)GluR $1_{\mathrm{o}}$ had a $\tau$ value that was intermediate between GluR1 $1_{\mathrm{o}}$ and GluR3 $3_{\mathrm{o}}$ and was statistically significantly different from the single-point mutant (Y714F)GluR1 $1_{\mathrm{o}}$ but not different from (R757G)GluR1 $1_{\text {, }}$, displaying a lack of additivity of effect on $\tau$ for these two amino acid residues. Yet, creation of the doublepoint mutant (Y716F, R757G)GluR1 completely converted the desensitization rate constant to a value that was not different from 


\begin{tabular}{|c|c|c|c|c|c|c|}
\hline Receptor & $\tau(\mathrm{msec})$ & $\tau_{\text {rec }}(\mathrm{msec})$ & $\tau_{\text {deact }}(\mathrm{msec})$ & $\mathrm{I}_{\text {peak }}(\mathrm{pA})$ & $\mathrm{I}_{\mathrm{ss}}\left(\% \mathrm{I}_{\text {peak }}\right)$ & $n$ \\
\hline Chimera 1 & $1.53 \pm 0.03^{* * *}$ & & & $30 \pm 20$ & $7 \pm 1$ & 5 \\
\hline Chimera 2 & $2.12 \pm 0.05^{* * *}$ & & & $78 \pm 37$ & $6 \pm 2$ & 5 \\
\hline Chimera 3 & $1.57 \pm 0.11^{* * *}$ & & & $107 \pm 17$ & $5 \pm 2$ & 7 \\
\hline Chimera 4 & $4.03 \pm 0.21^{\# \# \#}$ & & & $141 \pm 50$ & $9 \pm 2$ & 6 \\
\hline Chimera 5 & $3.82 \pm 0.15^{\# \# \#}$ & & & $109 \pm 36$ & $7 \pm 2$ & 5 \\
\hline Chimera 6 & $2.54 \pm 0.09^{\dagger \dagger \dagger}$ & & & $59 \pm 18$ & $8 \pm 2$ & 10 \\
\hline Chimera 7 & $2.51 \pm 0.16^{\dagger \dagger \dagger}$ & & & $49 \pm 10$ & $5 \pm 1$ & 6 \\
\hline GluR1 $1_{\mathrm{o}}$ & $3.84 \pm 0.12^{\# \# \#}$ & $155 \pm 16$ & $0.99 \pm 0.11$ & $60 \pm 13$ & $8 \pm 1$ & $13,10,10$ \\
\hline E665D & $3.63 \pm 0.22^{\# \# \#}$ & & & $42 \pm 10$ & $9 \pm 2$ & 6 \\
\hline A666S & $3.58 \pm 0.30^{\# \# \#}$ & & & $68 \pm 36$ & $7 \pm 1$ & 5 \\
\hline F681Y & $3.71 \pm 0.32^{\# \# \#}$ & & & $30 \pm 9$ & $6 \pm 1$ & 5 \\
\hline T686S & $3.57 \pm 0.12^{\# \# \#}$ & & & $40 \pm 11$ & $7 \pm 2$ & 6 \\
\hline V697T & $3.57 \pm 0.15^{\# \# \#}$ & & & $140 \pm 23$ & $6 \pm 1$ & 9 \\
\hline R698K & $3.86 \pm 0.15^{\# \# \#}$ & & & $82 \pm 17$ & $5 \pm 1$ & 5 \\
\hline E701A & $3.76 \pm 0.35^{\# \# \#}$ & & & $19 \pm 8$ & $9 \pm 1$ & 7 \\
\hline E702D & $3.83 \pm 0.30^{\# \# \#}$ & & & $102 \pm 25$ & $6 \pm 2$ & 7 \\
\hline M704V & $3.83 \pm 0.46^{\# \# \#}$ & & & $94 \pm 83$ & $5 \pm 2$ & 5 \\
\hline I705A & $3.87 \pm 0.44^{\# \# \#}$ & & & $181 \pm 27$ & $9 \pm 1$ & 7 \\
\hline $\mathrm{Y} 714 \mathrm{~F}$ & $3.04 \pm 0.21^{\# \# \#, * *}$ & & & $49 \pm 19$ & $6 \pm 2$ & 7 \\
\hline $\mathrm{Y} 716 \mathrm{~F}$ & $2.45 \pm 0.35^{* * *, \# \#}$ & $117 \pm 10$ & $0.94 \pm 0.11$ & $14 \pm 2$ & $9 \pm 1$ & $5,5,7$ \\
\hline $\mathrm{I} 748 \mathrm{~V}$ & $3.92 \pm 0.13^{\# \# \#}$ & & & $54 \pm 13$ & $9 \pm 1$ & 6 \\
\hline $\mathrm{R} 757 \mathrm{G}$ & $2.55 \pm 0.10^{\dagger \dagger \dagger}$ & $52 \pm 11^{*}$ & $1.13 \pm 0.06$ & $119 \pm 25$ & $5 \pm 1$ & $19,5,4$ \\
\hline P759A & $3.75 \pm 0.30^{\# \# \#}$ & & & $86 \pm 15$ & $7 \pm 1$ & 14 \\
\hline $\mathrm{Y} 714 \mathrm{~F}+\mathrm{Y} 716 \mathrm{~F}$ & $2.89 \pm 0.17^{\dagger \dagger \dagger}$ & $149 \pm 24$ & $1.02 \pm 0.08$ & $112 \pm 25$ & $9 \pm 2$ & $14,5,9$ \\
\hline $\mathrm{Y} 714 \mathrm{~F}+\mathrm{R} 757 \mathrm{G}$ & $2.49 \pm 0.12^{\dagger \dagger \dagger}$ & $60 \pm 6^{*}$ & $1.02 \pm 0.20$ & $128 \pm 60$ & $8 \pm 2$ & $10,5,4$ \\
\hline $\mathrm{Y} 716 \mathrm{~F}+\mathrm{R} 757 \mathrm{G}$ & $1.75 \pm 0.07^{* * *}$ & $56 \pm 19^{*}$ & $1.12 \pm 0.12$ & $54 \pm 14$ & $7 \pm 1$ & $7,7,4$ \\
\hline $\mathrm{Y} 714 \mathrm{~F}+\mathrm{Y} 716 \mathrm{~F}+\mathrm{R} 757 \mathrm{G}$ & $1.67 \pm 0.05^{* * *}$ & $90 \pm 9^{*}$ & $1.02 \pm 0.10$ & $102 \pm 30$ & $9 \pm 1$ & $21,8,9$ \\
\hline GluR3 & $1.49 \pm 0.06^{* * *}$ & $142 \pm 25$ & $1.05 \pm 0.09$ & $28 \pm 5$ & $8 \pm 2$ & $16,5,6$ \\
\hline F728Y & $1.19 \pm 0.04^{* * *, \neq}$ & & & $107 \pm 29$ & $8 \pm 2$ & 5 \\
\hline $\mathrm{F} 728 \mathrm{Y}+\mathrm{G} 769 \mathrm{R}$ & $1.84 \pm 0.10^{* * *, \neq, \S \S}$ & & & $138 \pm 29$ & $6 \pm 1$ & 10 \\
\hline GluR $4 c_{o}$ & $1.17 \pm 0.08^{* * *}$ & & & $120 \pm 34$ & $5 \pm 1$ & 9 \\
\hline F724Y & $0.95 \pm 0.03^{* * *, \#}$ & & & $61 \pm 33$ & $6 \pm 1$ & 6 \\
\hline G765R & $1.77 \pm 0.26^{* * *, \S, \text { ㅁㅁ }}$ & & & $33 \pm 17$ & $7 \pm 2$ & 6 \\
\hline $\mathrm{F} 724 \mathrm{Y}+\mathrm{G} 765 \mathrm{R}$ & $1.64 \pm 0.06^{* * *, \square \square \square}$ & & & $78 \pm 19$ & $5 \pm 2$ & 4 \\
\hline
\end{tabular}

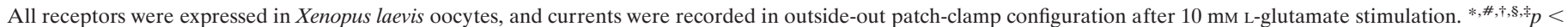
$0.05 ; * * \#, \S \S, \square \square<0.01 ; * * *, \# \# \#,+\dagger, \square \square \square p<0.001$.

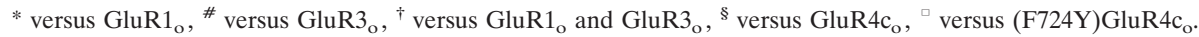

$n=$ number of eggs recorded for each parameter $\left(\tau, \tau_{\text {rec }}, \tau_{\text {deact }}\right)$.

GluR $3_{\mathrm{o}}$. The effects of the double mutations in this case are synergistic, because each of the single-point mutations only partially changed the $\tau$ value toward that of GluR $3_{\mathrm{o}}$. The triple-point mutant (Y714F, Y716F, R757G)GluR1 o was also evaluated and found not to be statistically different from GluR3 or from (Y716F, R757G)GluR1 $1_{\mathrm{o}}$, indicating that the effects of Y714F and Y716F exchange are not additive. Therefore, the two key amino acid residues that seem to be responsible for controlling $\tau$ in GluR $1_{\mathrm{o}}$ are R757 and Y716, although Y714 may have some small effect as well. It was of interest to see whether the complementary changes in GluR $3_{\mathrm{o}}$ could result in a slower desensitization rate, as seen for GluR1 $1_{\mathrm{o}}$. However, the mutants (F728Y)GluR3 $3_{\mathrm{o}}$ and (F728Y, G769R)GluR3 desensitized at rates that were not statistically significantly different from wild-type GluR3 o (Table 1). Similar results were obtained with the homologous mutations in GluR $4 c_{o}$, which also contains a phenylalanine at this position.

To test whether these point mutations have any effect on the rate of recovery from desensitization, $\tau_{\text {rec }}$ was measured for wild-type GluR1 $1_{o}$ and GluR2 ${ }_{o}$ as well as for several GluR1 mutants (Fig. 5, Table 1). Four mutants [(Y714F, Y716F, R757G)GluR1 $1_{\mathrm{o}}$, (Y714F, R757G)GluR1, (Y716F, R757G)GluR1 and $(\mathrm{R} 757 \mathrm{G})$ GluR1 $1_{\mathrm{o}}$ ] exhibited a faster recovery from desensitization than did wild type, whereas (Y714F, Y716F)GluR1 $1_{\mathrm{o}}$ and (Y716F)GluR1 $1_{\mathrm{o}}$ were indistinguishable from GluR1 $1_{\mathrm{o}}$. The data suggest that this $\tau_{\text {rec }}$ effect occurs because of the R/G site (Lomeli et al., 1994) and that the values are in the same range as reported previously for GluR1 $1_{\mathrm{o}}(147 \mathrm{msec})$ (Partin et al., 1996). This implies that Y714 or Y716 are not involved in recovery from desensitization. Interestingly, GluR $3_{\mathrm{o}}$ had a $\tau_{\text {rec }}$ that was not different from GluR $1_{\mathrm{o}}$, suggesting that residues in GluR $3_{\mathrm{o}}$ other than the $\mathrm{R} / \mathrm{G}$ site may be involved in controlling $\tau_{\text {rec }}$. These mutants and wild-type receptors were also evaluated with respect to their deactivation rate $\left(\tau_{\text {deact }}\right)$ after a brief $(1 \mathrm{msec})$ application of $10 \mathrm{~mm}$ L-glutamate (Fig. 5, Table 1$)$. The $\tau_{\text {deact }}$ value obtained here for GluR $1_{\mathrm{o}}$ is similar to that reported previously $(1.1 \pm 0.2$ msec, Mosbacher et al., 1994; $0.80 \pm 0.04 \mathrm{msec}$, Partin et al., 1996), and none of these mutants differed significantly from wild-type. 

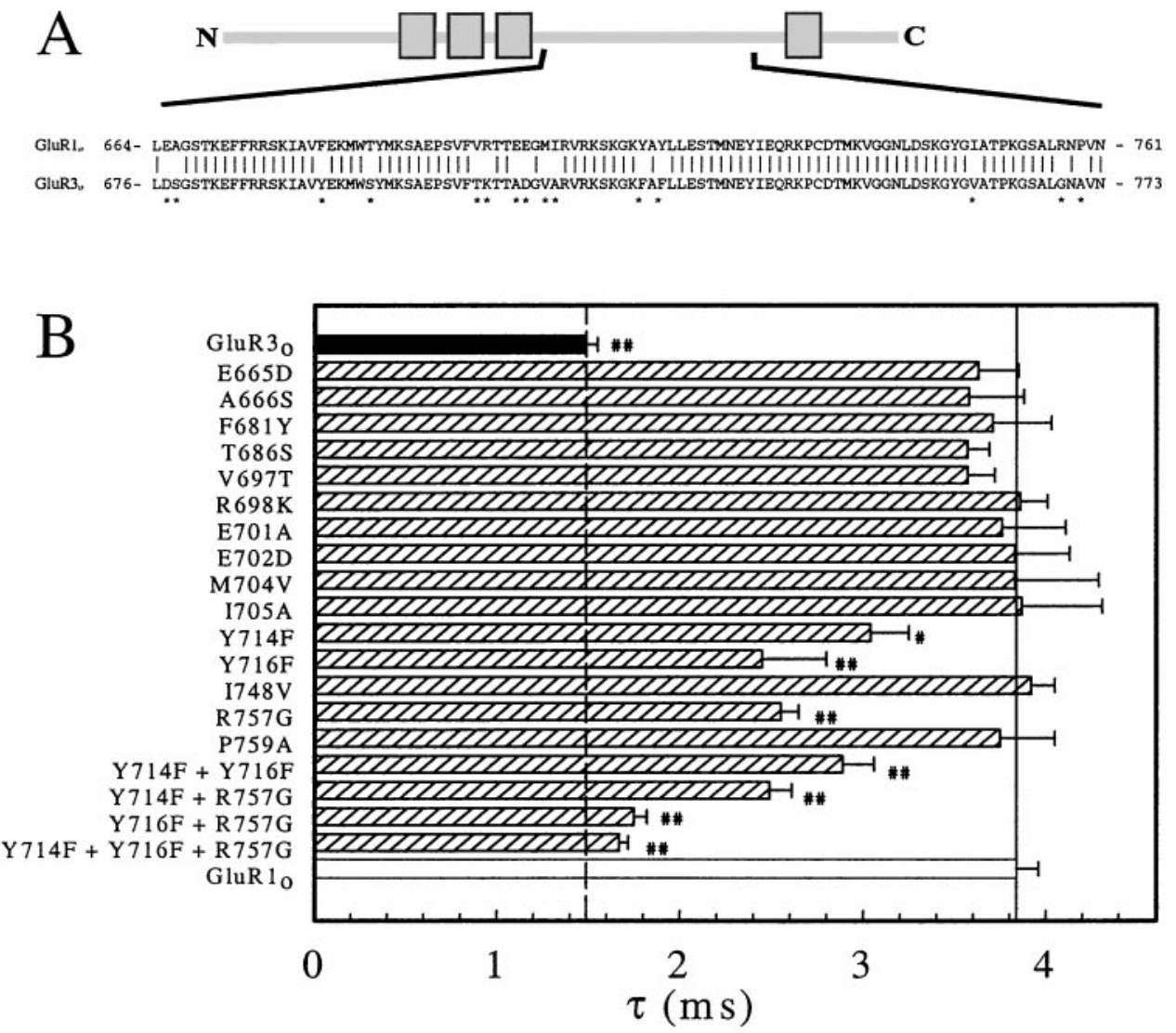

Figure 4. Desensitization at GluR1 1 S2 region point mutants. $A$, An alignment of GluR1 and GluR3 a amino acid sequences in the region between TMD III and TMD IV (S2 region). $N, \mathrm{~N}$ terminus; $C$, terminus; TMDs are represented by boxes. This section of the figure is not drawn to scale. $B$, A histogram of the mean desensitization rate constant $(\tau)$ for GluR1 $1_{\text {o }}$ point mutants, with amino acids numbered as in $A$. The $10-90 \%$ rise time for the double mutants (pooled) was $275 \pm 21 \mu$ sec compared with $343 \pm 39$ $\mu \mathrm{sec}$ for GluR1。 (10 fastest patches), which was not statistically significantly different. Significant differences versus GluR $1_{\mathrm{o}}$ are indicated as follows: ${ }^{\# \#} p<$ $0.001,{ }^{\#} p<0.01$.

\section{AMPAR pharmacology}

These $\mathrm{Y} / \mathrm{F}$ and $\mathrm{R} / \mathrm{G}$ exchanges were then evaluated with regard to effects on agonist potency $\left(\mathrm{EC}_{50}\right)$ and affinity $\left(K_{\mathrm{i}}\right)$. For the latter experiments, the mutants (Y716F, R757G)GluR1 (Y716F)GluR1 $1_{\mathrm{o}}$, (F728Y, G769R)GluR3 ${ }_{\mathrm{o}}$, and (F728Y)GluR3 were engineered into recombinant baculoviruses and expressed by infection in Sf9 cells. Receptor expression was verified by SDS-PAGE and Western immunoblotting as described previously (Nielsen et al., 1998), and all mutants had the same $M_{r}$ as the respective wild-type receptor (data not shown).

Whereas agonists such as AMPA, KA, and L-glutamate have little or no selectivity between GluR $1_{\mathrm{o}}$ and GluR3 $3_{\mathrm{o}}$ (Banke et al., 1997), $(R, S)$-BrHIBO exhibits an $\sim 28$-fold selectivity for GluR1。 $\left(\mathrm{EC}_{50}=7.2 \pm 2.8 \mu \mathrm{M} ; n=5\right)$ over GluR3 ${ }_{\mathrm{o}}\left(\mathrm{EC}_{50}=198 \pm 31 \mu \mathrm{M}\right.$; $n=5$ ) (Fig. 6A, Table 2). Interestingly, at the mutants (Y716F, R757G)GluR1,$\quad(Y 714 F, Y 716 F, \quad$ R757G)GluR1,$\quad$ and $(\mathrm{Y} 716 \mathrm{~F}) \mathrm{GluR}_{\mathrm{o}},(R, S)$-BrHIBO had a potency that was not statistically significantly different from that at GluR $3_{\mathrm{o}}$. Similarly, at the mutants (F728Y, G769R)GluR3 ${ }_{\text {o }}$ and (F728Y)GluR3 ${ }_{\mathrm{o}},(R, S)$ BrHIBO had a potency that was not different from GluR $1_{\mathrm{o}}$. These results imply that the $\mathrm{R} / \mathrm{G}$ site is not involved in this change in potency. Hence, the agonist potency for $(R, S)$ BrHIBO at GluR1, and GluR3 ${ }_{\text {o }}$ was interchanged by the Y716/ F728 point exchanges. In comparison, the potency of $(R, S)$ BrHIBO at (Y714F, R757G)GluR1。 was unchanged from wildtype GluR1 $1_{\mathrm{o}}$ (Table 2), also indicating that neither residue Y714 nor residue $\mathrm{R} 757$ are important for this switch in agonist potency.

In binding experiments made on Sf9 cell membranes expressing wild-type AMPARs, the compounds L-glutamate, L-quisqualate, AMPA, and KA exhibited little subtype selectivity (Table 2$)$. In contrast, $(R, S)$-BrHIBO showed a 69-fold selectivity for GluR1 $1_{\mathrm{o}}\left(K_{\mathrm{i}}=173 \pm 37 \mathrm{nM}\right)$ over GluR3 $3_{\mathrm{o}}\left(K_{\mathrm{i}}=12.0 \pm 2.4 \mu \mathrm{M}\right)$ (Fig. 6B, Table 2), which is in agreement with the higher potency of $(R, S)$-BrHIBO seen at GluR $1_{\mathrm{o}}$. $(R, S)$-BrHIBO had an affinity for the mutant (F728Y, G769R)GluR3 ${ }_{\mathrm{o}}$ that was not different from that at GluR $1_{\mathrm{o}}$ but was different from GluR $3_{\mathrm{o}}$. The affinity of $(R, S)$-BrHIBO at the mutant (Y716F, R757G)GluR1 $1_{\mathrm{o}}$ was different from that at both GluR3 $3_{\mathrm{o}}$ and GluR1 $1_{\mathrm{o}}$ but is clearly approaching the lower affinity seen at GluR $3_{\mathrm{o}}$. Therefore, these complementary mutations have effectively reversed the pharmacology of $(R, S)$-BrHIBO at GluR $1_{\mathrm{o}}$ and GluR $3_{\mathrm{o}}$. Yet there was no major change in the L-glutamate affinity at these mutants compared with the wild-type receptors. $(R, S)$-AMPA showed only a threefold lower affinity at (Y716F, R757G)GluR1 $1_{\mathrm{o}}$ compared with GluR $1_{o}$ and no change in affinity at (F728Y, G769R)GluR3 ${ }_{\text {o compared with GluR3 }}$. Because the R/G site is expected to be localized far away from the binding pocket in GluR1 $1_{\mathrm{o}}$ and GluR3 ${ }_{\mathrm{o}}$, as it is in GluR2 (Armstrong et al., 1998; Armstrong and Gouaux, 2000), the observed changes in binding affinity could most probably be attributed to the $\mathrm{Y} / \mathrm{F}$ site. This was verified by subsequent measurement of the affinity of $(R, S)$-BrHIBO at the mutant (Y716F)GluR $1_{\mathrm{o}}$, which was not different from (Y716F, R757G)GluR1 $1_{\mathrm{o}}$, and the mutant (F728Y)GluR3 $3_{o}$, which was not different from (F728Y, G769R)GluR3 o (Table 2). In contrast to BrHIBO, Y/F exchange had the opposite effect on the binding affinity of KA, causing a sevenfold decrease for GluR $3_{\mathrm{o}}$ and a 14-fold increase for GluR $1_{\mathrm{o}}$. This suggests that BrHIBO interacts very differently with these residues than does KA.

Not unexpectedly, it was found that $\operatorname{GluR} 2_{\mathrm{o}}(\mathrm{R})$ also binds $(R, S)$-BrHIBO with an affinity that is about the same as that of GluR1 $1_{\text {o }}$ (Coquelle et al., 2000), because GluR2 has a tyrosine in 
A

Figure 5. Deactivation and recovery from desensitization. $A$, Recovery from desensitization in an outside-out patch expressing wild-type GluR1 $1_{\mathrm{o}}$ receptors. L-glutamate $(10 \mathrm{~mm})$ was applied for 1 msec at the following time intervals (in msec): $0,50,100,150,200,250,300,350$, $400,500,600$, and $800 . \tau_{\text {rec }}$ was $152 \mathrm{msec}$ for this experiment. $B$, Histogram showing recovery from desensitization for GluR $1_{\mathrm{o}}$ and the multiple-point mutants. $C$, Deactivation and desensitization in an outside-out patch expressing GluR $1_{\mathrm{o}}$. Deactivation and desensitization were obtained by application of $10 \mathrm{~mm}$ L-glutamate for 1 and $100 \mathrm{msec}$, respectively, as shown above the traces. Traces were fitted to a monoexponential equation with the following results: $\tau_{\text {deact }}, 0.98$ msec; $\tau, 3.12$ msec. $D$, Histogram showing deactivation rate constants for GluR $1_{\mathrm{o}}$, GluR $3_{\mathrm{o}}$, and GluR $1_{\mathrm{o}}$ mutants. ${ }^{*} p<0.05$, significantly different from GluR $1_{\mathrm{o}}$.

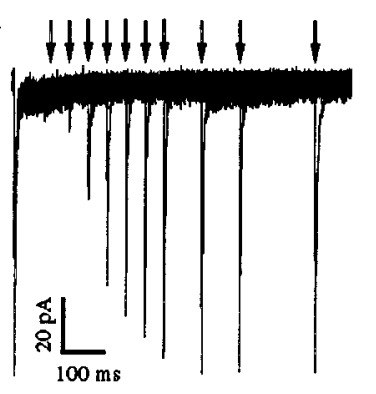

C

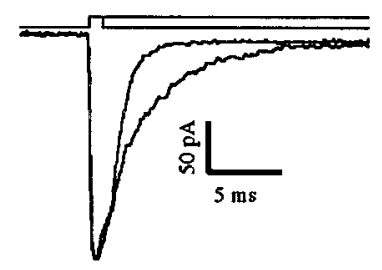

B
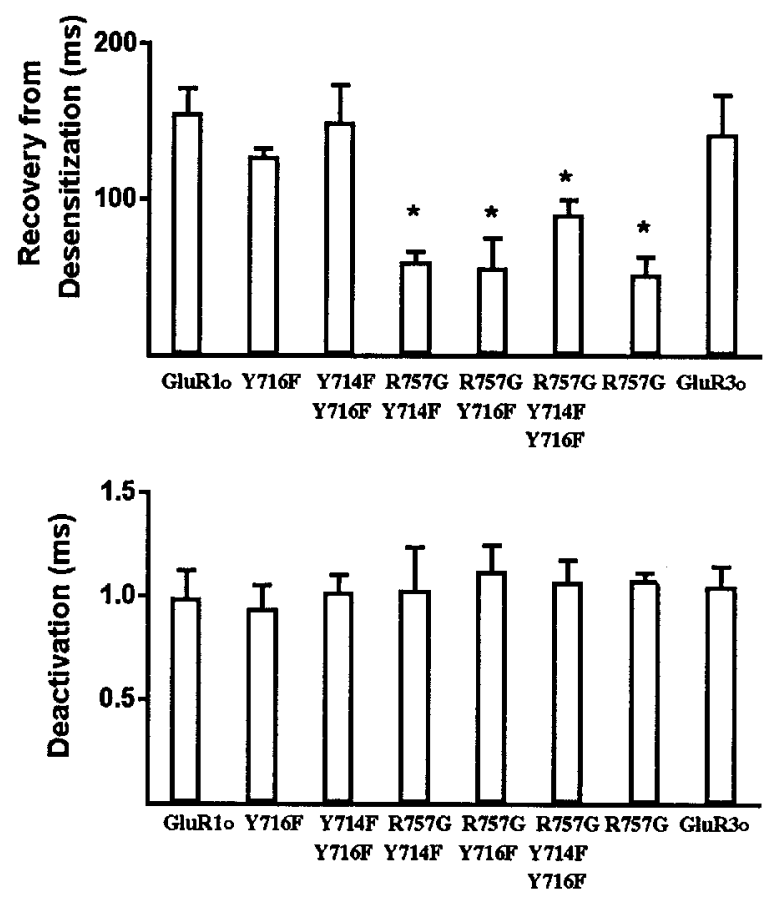

the position homologous to Y716 of GluR $1_{\mathrm{o}}$. It is predicted that GluR4 $4_{\mathrm{o}}$ should have a low affinity for these analogs, similar to GluR $3_{\mathrm{o}}$, because a phenylalanine residue is present at this position in GluR4 $4_{\mathrm{o}}$. Furthermore, this similarity in GluR1/GluR2 sensitivity to BrHIBO suggests that use of the GluR2-S1S2 binding site model may provide relevant information about the GluR1 binding site.

\section{Molecular modeling of GluR1 and GluR3 binding sites}

To improve our understanding of the reasons for these differences in binding and desensitization between GluR $1_{\mathrm{o}}$ and GluR $3_{\mathrm{o}}$, homology models of the ligand binding domains of GluR $1_{\mathrm{o}}$, GluR $3_{\mathrm{o}}$, and GluR $4_{\mathrm{o}}$ were generated using the $\mathrm{x}$-ray crystal structures of GluR2-S1S2 constructs (Armstrong et al., 1998; Armstrong and Gouaux, 2000). Seven amino acids residues interact directly with the ligand within the GluR2-S1S2 constructs: Y450, P478, T480, and R485 from S1, and S654, T655, and E705 from S2. These correspond to the homologous residues Y464, P492, T494, R499, S668, T669, and E719 in GluR1 (numbering from the initiation methionine) or with Y474, P502, T504, R509, S680, T681 and E731 in GluR3. As expected from the high amino acid sequence identity of these proteins within the binding site, all seven of the identified ligand-binding residues in GluR2-S1S2 are predicted to occupy virtually the same spatial positions in GluR1 and GluR3. The question arises as to why AMPA has the same affinity for both GluR1。 and GluR3 3 while homoibotenic acid analogues such as BrHIBO and MeHIBO exhibit subtype selectivity (Coquelle et al., 2000). To investigate this question, L-glutamate, AMPA, and BrHIBO were docked into the binding sites of the models of GluR1 and GluR3 (Fig. 7). Docking was guided by the experimentally observed binding modes of AMPA and glutamate to GluR2-S1S2J (Armstrong and Gouaux, 2000).

The crystal structures of the GluR2-S1S2 constructs show that a number of water molecules are present within the binding site and that, to some extent, their positions depend on the nature of the bound ligand. On the basis of the very high degree of homology, it is most probable that the water matrix observed within
GluR2-S1S2 for a given ligand is also present in GluR1 and GluR3. This hypothesis was confirmed by GRID analysis. On this basis, water structure was added to the models within a radius of $8.5 \AA$ of the ligand. The water molecules W1-W3 are of most importance in the present context. In the case of the docking of BrHIBO (for which no GluR2-S1S2 crystal structure has yet been published), it was necessary to relocate W2. Note that for both BrHIBO and AMPA to interact with the same amino acid residues within GluR2-S1S2, the heterocyclic rings of BrHIBO and AMPA must adopt different orientations. In particular, the negatively charged oxygens (labeled $\mathrm{O} 1$ in Fig. 7) of these two ligands must point in opposite directions (Christensen et al., 1992; Greenwood et al., 1998). The O2 of BrHIBO overlaps closely with the position of W2 in the AMPA complex, but by preserving the position of $\mathrm{W} 2$ relative to the flipped isoxazole ring of $\mathrm{BrHIBO}$, this water molecule comes to occupy a zone close to that of W2 in the glutamate structure. This is confirmed to be a favorable site for water by GRID analysis. Because hydrogen atoms are undetectable by protein crystallography, and therefore not included in the experimental GluR2-S1S2 structures, their positions must be determined by calculation. Where necessary, Monte Carlo simulations were used to resolve ambiguities in assigning the pattern of $\mathrm{H}$ bonding. The positions of selected protons and the alignment of their $\mathrm{H}$ bonds are indicated in Figure 7.

\section{DISCUSSION}

\section{Receptor desensitization}

Agonist binding can cause iGluRs to either open or desensitize (assume a closed state). However, little is known about how agonist binding is coupled to channel gating. Here, we took advantage of the known differences in desensitization properties of the AMPAR subunits (Lomeli et al., 1994; Banke et al., 1997; Stern-Bach et al., 1998) for an investigation of the underlying molecular mechanism or mechanisms involved in GluR $1_{\mathrm{o}}$ desensitization. GluR $1_{\mathrm{o}}$ was chosen as an example of an AMPAR 

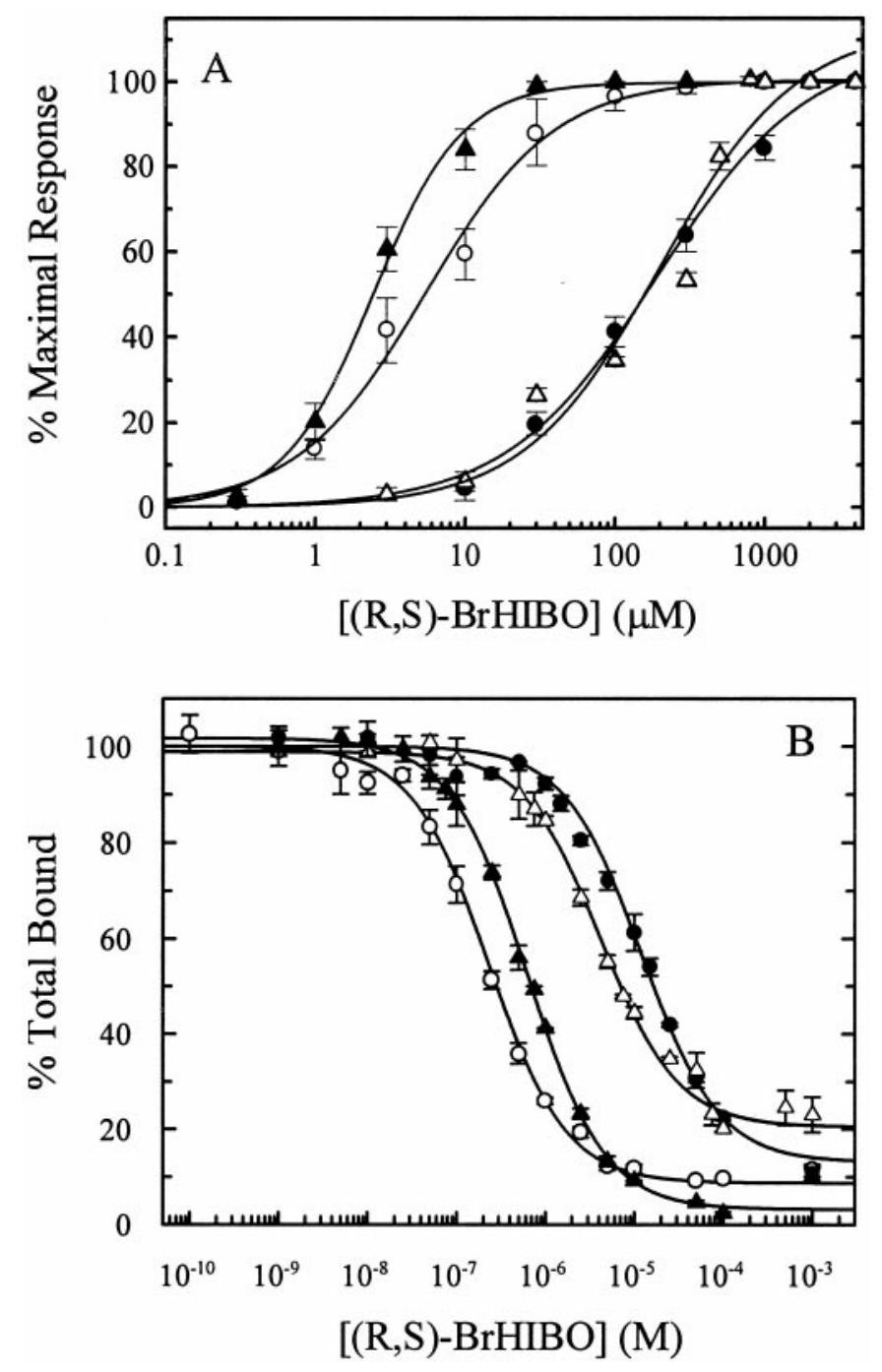

Figure 6. Pharmacology of mutant and wild-type AMPARs. Potency $\left(\mathrm{EC}_{50}\right)$ and affinity $\left(K_{\mathrm{i}}\right)$ of $(R, S)$-BrHIBO at wild-type and mutant AMPARs are shown. $A$, Receptors were expressed in $X$. laevis oocytes, and steady-state currents were measured after application of increasing concentrations of $(R, S)$ - $\mathrm{BrHIBO} . \mathrm{EC}_{50}$ was determined by fitting data to a logistic equation as described in Materials and Methods. Curves are mean \pm SEM from 5 to 16 oocytes. $B$, Receptors were expressed in Sf9 cell membranes and drug affinity was measured by $(R, S)-\left[{ }^{3} \mathrm{H}\right] \mathrm{AMPA}$ competition binding assays. $K_{\mathrm{i}}$ was determined by nonlinear, iterative fitting of the data as described in Materials and Methods. Shown are the mean \pm SD of triplicate determinations from single experiments (replicated 3-6 times). $\bigcirc$, GluR1 $1_{\mathrm{o}}\left(\mathrm{EC}_{50}=7.2 \pm 2.8 \mu \mathrm{M} ; n=5 ; K_{\mathrm{i}}=183 \mathrm{nM}\right)$; - , GluR3 ${ }_{\mathrm{o}}\left(\mathrm{EC}_{50}=198 \pm 31 \mu \mathrm{M} ; n=5 ; K_{\mathrm{i}}=9.53 \mu \mathrm{M}\right) ; \Delta$, (Y716F)GluR1 ${ }_{\mathrm{o}}\left(\mathrm{EC}_{50}=200 \pm 27 \mu \mathrm{M} ; n=16 ; K_{\mathrm{i}}=3.69 \mu \mathrm{M}\right) ; \boldsymbol{\Delta}$, $\left(\right.$ F728Y)GluR3 ${ }_{\mathrm{o}}\left(\mathrm{EC}_{50}=2.6 \pm 0.4 \mu \mathrm{M} ; n=5 ; K_{\mathrm{i}}=423 \mathrm{nM}\right)$.

subunit exhibiting a slow desensitization rate and GluR3 os an example of one having a fast rate. Evaluation of a series of chimeric receptors focused on exchange of amino acid sequences in the $\mathrm{S} 2$ region of GluR $1_{\mathrm{o}}$ because previous evidence had suggested that amino acids in the S2 region were important for GluR $1_{\mathrm{o}}$ desensitization properties (Mano et al., 1996; Banke et al., 1997). The single-point GluR1 $1_{\mathrm{o}}$ mutations Y714F and Y716F each created receptors having a faster $\tau$ than wild type, and point exchanges at other residues in S2 that differ between GluR $1_{\mathrm{o}}$ and GluR3 $3_{\mathrm{o}}$ had no effect on $\tau$, except when GluR $1_{\mathrm{o}}$ or GluR $3_{\mathrm{o}}$ were exchanged at the $\mathrm{R} / \mathrm{G}$ site, which had been identified previously as being important for controlling AMPAR desensitization properties (Lomeli et al., 1994). However, only a double exchange of Y716F plus R757G in GluR1 $1_{\text {o }}$ converted the desensitization rate to that seen with GluR3 $3_{\mathrm{o}}$. Therefore, we have identified that residue Y716 also somehow plays a very important role in the desensitization mechanism of GluR $1_{\mathrm{o}}$ and that neighboring Y714 can weakly interact with this process also, but cannot completely substitute for Y716. Remarkably, the complementary mutations in GluR $3_{\mathrm{o}}$ did not result in an increase in $\tau$ toward that of GluR $1_{o}$; rather, there was little effect on $\tau$. Our interpretation of these results is that the desensitization mechanism or mechanisms of the AMPAR subunits may not be entirely the same, at least with respect to the subunit amino acid residues that are involved. It is likely that other amino acid residues in the S1 region, or perhaps even residues $\mathrm{N}$-terminal to $\mathrm{S} 1$, are involved in the desensitization mechanism. Our own data with chimera 2 and other mutagenesis studies (Uchino et al., 1992; Mano et al., 1996; Stern-Bach et al., 1998) support this interpretation.

Residues Y714 and Y716 are not involved in recovery from desensitization or deactivation but seem to be specifically involved in controlling the rate of GluR $1_{\text {o }}$ desensitization. The deactivation rate constant $\left(\tau_{\text {deact }}\right)$ for L-glutamate at GluR1 measured in this study is in good agreement with the values given in the literature (Mosbacher et al., 1994; Partin et al., 1996). However, no changes in $\tau_{\text {deact }}$ were observed with the mutant GluR1 $1_{\mathrm{o}}$ receptors. In contrast, all of the multiple-point GluR1 mutants containing the exchange $\mathrm{R} 757 \mathrm{G}$ exhibited faster recovery times than wild-type GluR $1_{\mathrm{o}}$, whereas neither the double exchange of Y714F plus Y716F nor the Y716F single exchange altered $\tau_{\text {rec }}$. This is consistent with the finding that the $\mathrm{R} / \mathrm{G}$ site controls recovery from desensitization in GluR $1_{\mathrm{o}}$.

\section{Binding site interactions}

In addition to effects on the time course of receptor desensitization and deactivation, it was a possibility that the $\mathrm{Y} / \mathrm{F}$ exchange in GluR1 $1_{\mathrm{o}}$ was somehow directly affecting agonist binding. Previous studies have shown that the $\mathrm{S} 1$ region and the $\mathrm{N}$-terminal portion of the S2 region are involved in ligand binding (Uchino et al., 1992; Stern-Bach et al., 1994; Li et al., 1995; Mano et al., 1996). Subsequently, the x-ray crystal structures were solved for both the ligand-bound and unbound (apo) versions of soluble GluR2-S1S2 binding site constructs (Armstrong et al., 1998; Armstrong and Gouaux, 2000). This indicated that the C-terminal region of S2, which includes the flip/flop region as well as the $R / G$ site, is located far away from the binding pocket, on the solvent-exposed surface of the protein. In contrast, residue Y716 lies in the $\mathrm{N}$-terminal part of the $\mathrm{S} 2$ region of GluR $1_{\mathrm{o}}$, within the binding pocket. So, could an exchange of binding site properties between GluR $1_{\mathrm{o}}$ and GluR3 $3_{\mathrm{o}}$ be seen on Y/F exchange?

Whereas most agonists at AMPARs show little or no subtype selectivity, $(R, S)$-BrHIBO exhibited a 28-fold preference for GluR $1_{\mathrm{o}}$ compared with GluR3 $3_{\mathrm{o}}$ in terms of potency $\left(\mathrm{EC}_{50}\right)$ and a 69 -fold preference in terms of affinity $\left(K_{\mathrm{i}}\right)$. The fact that both BrHIBO potency and affinity could be transposed by the $\mathrm{Y} / \mathrm{F}$ exchange between GluR1 $1_{o}$ and GluR3 $3_{o}$ leads to the conclusion that Y716 does interact in some manner with $(R, S)$-BrHIBO in the GluR $1_{\mathrm{o}}$ binding domain. Because no change in $\mathrm{EC}_{50}$, compared with wild type, was observed with the mutant (Y714F, R757G)GluR1 $1_{\mathrm{o}}$, it is also concluded that the Y714 residue is not involved in agonist interactions. Therefore, Y716 seems to play a key role in determining both the slower desensitization rate of GluR1 $1_{o}$ and the higher affinity of a subtype-selective agonist. 
Table 2. Agonist potencies and affinities at wild-type and mutant AMPARs

\begin{tabular}{|c|c|c|c|c|c|c|}
\hline \multirow[b]{2}{*}{ Receptor/drug } & \multicolumn{2}{|c|}{ L-glutamate ${ }^{a}$} & \multicolumn{2}{|l|}{ Kainate $^{\mathrm{a}}$} & \multicolumn{2}{|c|}{ L-quisqualate } \\
\hline & $K_{\mathrm{i}}(\mathrm{nM})$ & $n_{\mathrm{H}}$ & $K_{\mathrm{i}}(\mathrm{nM})$ & $n_{\mathrm{H}}$ & $K_{\mathrm{i}}(\mathrm{nM})$ & $n_{\mathrm{H}}$ \\
\hline GluR3 & $249 \pm 7^{b}$ & $1.10 \pm 0.03$ & $1,980 \pm 170$ & $0.94 \pm 0.04$ & $21.9 \pm 2.5^{\mathrm{c}}$ & $1.01 \pm 0.05$ \\
\hline (F728Y, G769R)GluR3 & $168 \pm 7$ & $1.11 \pm 0.07$ & $23,300 \pm 990^{\mathrm{c}, \mathrm{d}, \mathrm{f}}$ & $0.90 \pm 0.03$ & $8.1 \pm 1.7^{\mathrm{d}}$ & $1.00 \pm 0.07$ \\
\hline (F728Y)GluR3 & $159 \pm 7$ & $1.01 \pm 0.02$ & $14,700 \pm 1,800^{\mathrm{c}, \mathrm{d}}$ & $0.93 \pm 0.03$ & & \\
\hline GluR1 $1_{\mathrm{o}}$ & $169 \pm 13$ & $0.93 \pm 0.05$ & $478 \pm 38$ & $0.85 \pm 0.01$ & $4.7 \pm 0.8$ & $1.07 \pm 0.06$ \\
\hline (Y716F, R757G)GluR1 & $149 \pm 12$ & $1.20 \pm 0.22$ & $25 \pm 5^{\mathrm{d}-\mathrm{f}}$ & $1.26 \pm 0.15$ & $14.7 \pm 2.8^{c}$ & $1.00 \pm 0.07$ \\
\hline$(\mathrm{Y} 716 \mathrm{~F}) \mathrm{GluR} 1_{\mathrm{o}}$ & & & $34.4 \pm 4.5^{\mathrm{e}, \mathrm{f}}$ & $0.97 \pm 0.02$ & & \\
\hline
\end{tabular}

(Y714F, R757G)GluR1。

(Y714F, Y716F, R757G)GluR1。

${ }^{a} K_{\mathrm{i}}$ values at GluR1 $1_{\mathrm{o}}$ and GluR3 ${ }_{\mathrm{o}}$ are taken from Nielsen et al. (1998).

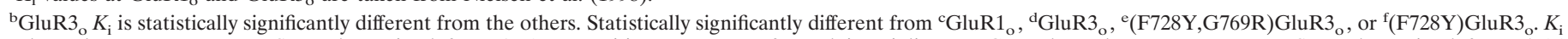

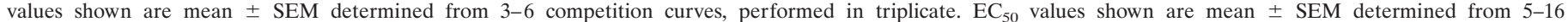
concentration-response curves. $n_{\mathrm{H}}$ is Hill coefficient (mean \pm SEM).

Table 2. Continued

$(R, S)-\mathrm{AMPA}^{\mathrm{a}}$

\begin{tabular}{rl}
\hline \multicolumn{1}{c}{$(\mathrm{nM})$} & $n_{\mathrm{H}}$ \\
\hline $20.6 \pm 1.1$ & $0.99 \pm 0.04$ \\
$10.0 \pm 1.8$ & $1.02 \pm 0.01$ \\
$7.6 \pm 0.7$ & $1.04 \pm 0.02$ \\
$21.9 \pm 1.8$ & $0.96 \pm 0.05$ \\
$66 \pm 6^{\mathrm{c}-\mathrm{f}}$ & $0.99 \pm 0.12$ \\
$87 \pm 8^{\mathrm{c}-\mathrm{f}}$ & $0.98 \pm 0.05$
\end{tabular}

$(R, S)$-BrHIBO

\begin{tabular}{cl}
\hline$K_{\mathrm{i}}(\mathrm{nM})$ & $n_{\mathrm{H}}$ \\
$12,000 \pm 2,380$ & $0.92 \pm 0.03$ \\
$427 \pm 27^{\mathrm{d}}$ & $0.93 \pm 0.01$ \\
$364 \pm 25^{\mathrm{d}}$ & $0.97 \pm 0.04$ \\
$173 \pm 37^{\mathrm{d}}$ & $0.85 \pm 0.10$ \\
$4,050 \pm 410^{\mathrm{c}, \mathrm{d}}$ & $1.00 \pm 0.15$ \\
$3,400 \pm 190^{\mathrm{c}, \mathrm{d}}$ & $1.04 \pm 0.05$
\end{tabular}

$(R, S)$-BrHIBO

\begin{tabular}{cl}
\hline $\mathrm{EC}_{50}(\mu \mathrm{M})$ & $n_{\mathrm{H}}$ \\
$198 \pm 31$ & $0.89 \pm 0.05$ \\
$23 \pm 6^{\mathrm{d}}$ & $1.18 \pm 0.05$ \\
$2.6 \pm 0.4^{\mathrm{d}}$ & $1.53 \pm 12$ \\
$7.2 \pm 2.8^{\mathrm{d}}$ & $1.10 \pm 0.09$ \\
$184 \pm 63^{\mathrm{c}, \mathrm{e}}$ & $0.76 \pm 0.08$ \\
$200 \pm 27^{\mathrm{c}, \mathrm{e}, \mathrm{f}}$ & $0.95 \pm 0.05$ \\
$8.6 \pm 4.0^{\mathrm{d}}$ & $0.99 \pm 0.21$ \\
$141 \pm 23^{\mathrm{c}}$ & $1.01 \pm 0.15$
\end{tabular}

${ }^{\mathrm{a}} K_{\mathrm{i}}$ values at GluR1 $1_{\mathrm{o}}$ and GluR3 $3_{\mathrm{o}}$ are taken from Nielsen et al. (1998).

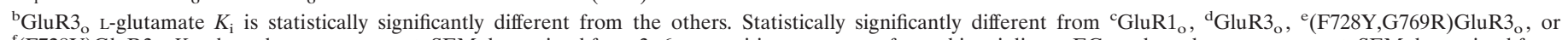

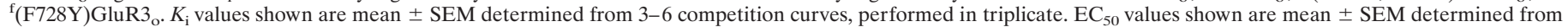
5-16 concentration-response curves. $n_{\mathrm{H}}$ is Hill coefficient (mean $\pm \mathrm{SEM}$ ).

This indicates that there can indeed be some mechanistic link between agonist binding and receptor desensitization. A connection between binding and desensitization is also suggested from recently published GluR2-S1S2 x-ray crystal structure data (Armstrong and Gouaux, 2000), where a correlation is seen between the extent of S1-S2 domain closure produced by a ligand and the extent of desensitization experimentally observed for that ligand.

\section{Molecular modeling}

Armstrong et al. (1998) predict that E402 (E416 in GluR1 $)$ of the $\mathrm{S} 1$ region interacts with $\mathrm{T} 686$ (T700 in GluR $1_{\mathrm{o}}$ ) of the $\mathrm{S} 2$ region via an $\mathrm{H}$ bond helping to stabilize the closed conformation. This may be thought of as an interdomain "lock" of the type suggested by Abele et al. (2000). We therefore came to focus on the hydrogen-bonded connection of the ligand to this lock through $\mathrm{W} 3$ and, in particular, how the nonconserved aromatic residue $(\mathrm{Y} / \mathrm{F})$ proximal to $\mathrm{W} 3$ influences network stability. By inspection, it is clear that W3 plays a critical role connecting ligand and lock, although its role is lessened in the case of glutamate binding by the interposed W2. Glutamate assigns an equal charge to both of its distal carboxylate oxygens, whereas AMPA and BrHIBO present a greater charge on $\mathrm{O} 1$ and less on the ring nitrogen. BrHIBO directs a negatively charged oxygen toward W3, whereas AMPA presents the lesser-charged nitrogen. At the same time, the acidity of the $\mathrm{W} 3$ proton forming an $\mathrm{H}$ bond to the ring is affected by Y716. Exchange to a phenylalanine abolishes the $\mathrm{H}$-bond donation to $\mathrm{W} 3$, causing a net decrease of positive charge on the proton in question and thus decreasing the strength of the $\mathrm{H}$ bond it makes with the ring. Therefore, the binding of HIBO derivatives ought to be more sensitive than that of AMPA or glutamate to this $\mathrm{Y} / \mathrm{F}$ position because they present the more strongly charged $\mathrm{O} 1$ to this $\mathrm{W} 3$ proton. Further modeling was undertaken to quantify this.

Cooperative $\mathrm{H}$ bonding is a subtle electronic effect requiring the use of quantum mechanics for adequate modeling (Masella and Flament, 2000). Therefore, we conducted high-level $a b$ initio calculations on a simplified model of the region around W3. Dimethylisoxazolol was chosen to represent both MeHIBO and AMPA to allow more accurate perturbative calculations rather than attempting to compensate for the presence of bromine (Fig. 8 ). The calculations show clearly that breaking the $\mathrm{H}$ bond between the phenyl ring and W3 causes a decrease in the acidity of the hydrogen-bonding W3 proton (Mulliken population analysis gives a difference of 0.02 charge units for both I and II). It is also clear that the presence or absence of the hydroxyl has quite a different effect on the total energies of models I and II: the tyrosine-OH of GluR1 lends more stability when the strongly negative $\mathrm{O} 1$ is proximal to $\mathrm{W} 3$. The difference in the relative stabilities is $1.65 \mathrm{kcal} / \mathrm{mol}$. By using the proportionality factor of 
A

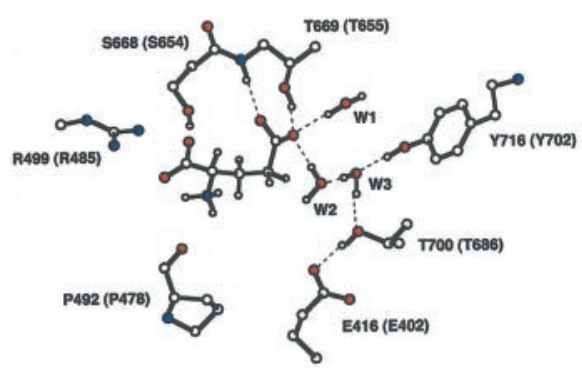

B

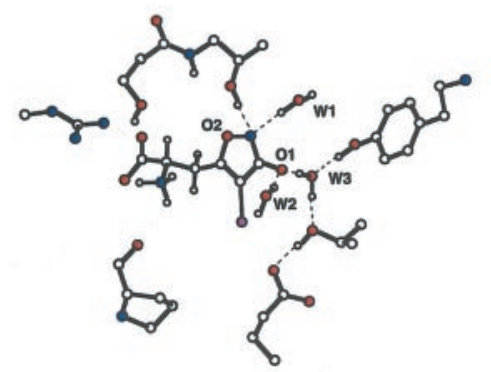

C

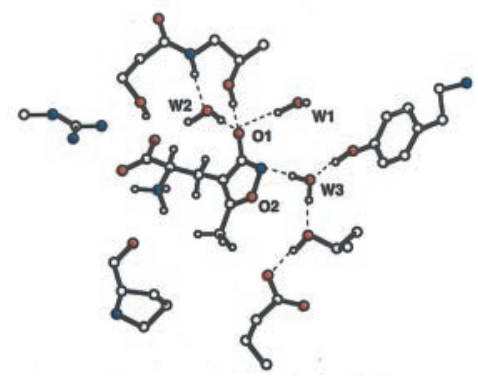

D

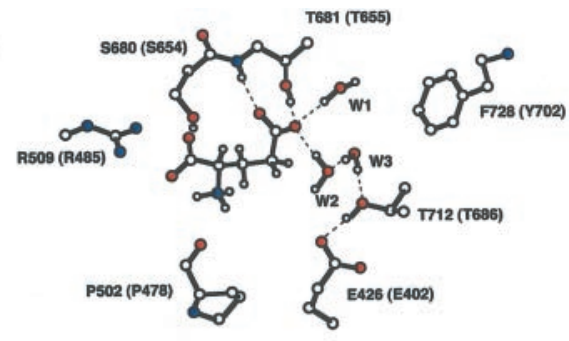

E

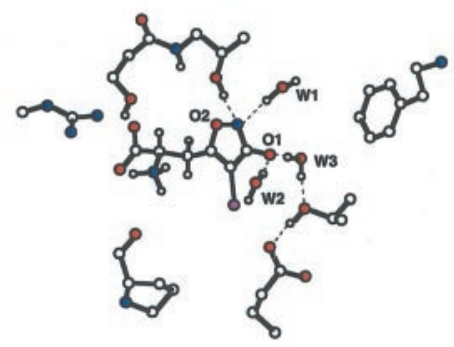

$\mathbf{F}$

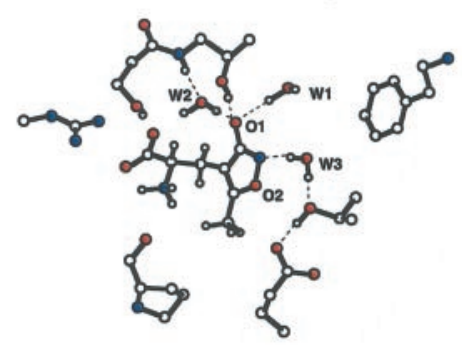

Figure 7. Binding site models. Models of L-glutamate $(A, D), \quad(S)$ BrHIBO $(B, E)$, and $(S)$-AMPA $(C$, $F)$ binding to GluR1 $1_{\mathrm{o}}(A-C)$ and GluR3。 $(D-F)$. The seven amino acid residues that have been shown to interact directly with ligands in the GluR2-S1S2 constructs correspond to the homologous residues Y464, P492, T494, R499, S668, T669, and E719 in GluR $1_{\mathrm{o}}$ (numbering from the initiation methionine) or with Y474, P502, T504, R509, S680, T681, and E731 in GluR3 . Residues are numbered (in $A$ and $D$ ), with the homologous GluR2 residue (Armstrong et al., 1998) indicated in parentheses. Some residues have been removed for clarity. Hydrogen bonds are denoted by dashed lines. $\mathrm{W} 1, \mathrm{~W} 2$, and $\mathrm{W} 3$ are binding site water molecules. O1 represents the hydroxyl group of AMPA or BrHIBO and $\mathrm{O} 2$ is the isoxazole oxygen.
1.36 to convert kilocalories per mole to $\log$ units at $298^{\circ} \mathrm{K}$, the net result is a prediction that the ratio between the selectivities of MeHIBO and AMPA at GluR1 versus GluR3 will be 16:1. Given that AMPA is roughly equipotent at both receptors, MeHIBO is predicted to bind 16 times more weakly at GluR $3_{\mathrm{o}}$ than GluR $1_{\mathrm{o}}$. This finding is in excellent agreement with the experimentally observed binding affinities of $\mathrm{MeHIBO}\left(K_{\mathrm{i}}=471 \pm 134 \mathrm{~nm}\right.$ at
GluR1 $1_{\mathrm{o}}$ and $7270 \pm 2200 \mathrm{~nm}$ at GluR3 $3_{\mathrm{o}}$ ) (Coquelle et al., 2000). Therefore, we conclude that the observed binding selectivity of the HIBO derivatives for GluR1 over GluR3 resides primarily in the effect of the $\mathrm{Y} / \mathrm{F}$ position on the hydrogen-bonding network linking the ligand with W3 to Y716 in GluR1. Neither glutamate nor AMPA show this susceptibility because of the weaker links between W3 and the ligand and, in the latter case, because of a

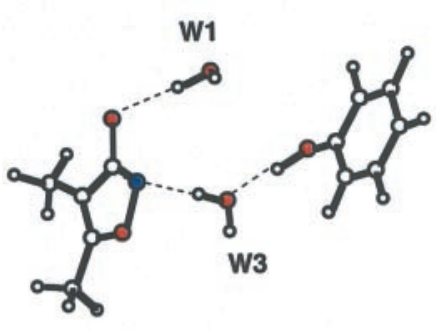

I-TYR

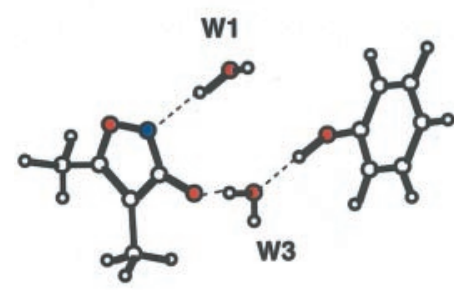

II-TYR

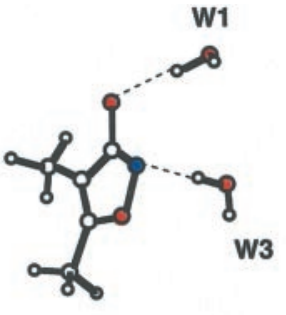

I-PHE

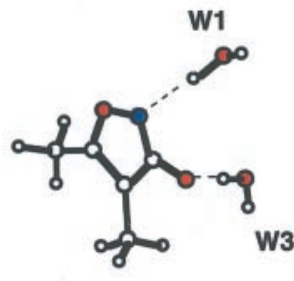

II-PHE

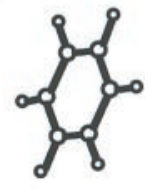

Figure 8. Ab initio modeling of ligand binding. Simplified models of AMPA (I) and MeHIBO (II) binding to GluR1 (TYR) and GluR3 (PHE) under constrained optimization according to $a b$ initio molecular orbital theory (see Materials and Methods). Quantum chemical energy calculations yield total energies (Hartree) at B3LYP/6-31+G(d): I-TYR, -859.7460; II-TYR, -859.7462; I-PHE, -784.5093; II-PHE, -784.5069 . Relative energy differences: TYR $\Delta \mathrm{E},-0.18 \mathrm{kcal} /$ $\mathrm{mol}$; PHE $\Delta \mathrm{E},+1.47 \mathrm{kcal} / \mathrm{mol}$. 
rather weak connection involving $\mathrm{W} 2$, for which only a small decrease in affinity is observed.

Finally, because the water molecule W3 connects Y716 in GluR1 $1_{\text {o }}$ (Fig. $7 A-C$ ) with the T700-E416 $\mathrm{H}$ bond, it is also probable that the water structure and $\mathrm{H}$-bond matrix, along with the altered volume occupied by tyrosine versus phenylalanine, influence the desensitization properties of the receptor, as observed here in the case of L-glutamate. Further refinements of our models, including quantum mechanical calculations of the bond energy of the T700-E416 H bond, are underway and should shed more light on the role of this region in controlling desensitization as well as binding.

\section{REFERENCES}

Abele R, Keinänen K, Madden D (2000) Agonist-induced isomerization in a glutamate receptor ligand-binding domain. J Biol Chem 275:21355-21363.

Armstrong N, Gouaux E (2000) Mechanisms for activation and antagonism of an AMPA-sensitive glutamate receptor: crystal structures of the GluR2 ligand binding core. Neuron 28:165-181.

Armstrong N, Sun Y, Chen GQ, Gouaux E (1998) Structure of a glutamate-receptor ligand-binding core in complex with kainate. Nature 395:913-917.

Banke TG, Schousboe A, Pickering DS (1997) Comparison of the agonist binding site of homomeric, heteromeric, and chimeric GluR $1_{\mathrm{o}}$ and

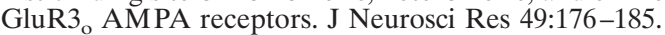

Bittigau P, Ikonomidou C (1997) Glutamate in neurologic diseases. J Child Neurol 2:471-485.

Brose N, Huntley GW, Stern-Bach Y, Sharma G, Morrison JH, Heinemann SF (1994) Differential assembly of coexpressed glutamate receptor subunits in neurons of rat cerebral cortex. J Biol Chem 269:16780-16784.

Christensen IT, Ebert B, Madsen U, Nielsen B, Brehm L, KrogsgaardLarsen P (1992) Excitatory amino acid receptor ligands. Synthesis and biological activity of 3-isoxazolol amino acids structurally related to homoibotenic acid. J Med Chem 35:3512-3519.

Coquelle T, Christensen JK, Banke TG, Madsen U, Schousboe A, Pickering DS (2000) Agonist discrimination between AMPA receptor subtypes. NeuroReport 11:2643-2648.

Dingledine R, Borges K, Bowie D, Traynelis SF (1999) The glutamate receptor ion channels. Pharmacol Rev 51:7-61.

Ferrer-Montiel AV, Montal M (1996) Pentameric subunit stoichiometry of a neuronal glutamate receptor. Proc Natl Acad Sci USA 93:2741-2744.

Goodford PJ (1985) A computational procedure for determining energetically favorable binding sites on biologically important macromolecules J Med Chem 28:849-857.

Greenwood JR, Vaccarella G, Capper HR, Allan RD, Johnston GAR (1998) Heterocycles as bioisosteres for the $\omega$-carboxylate moiety of glutamate in AMPA receptor agonists: a review and theoretical study. Internet J Chem http:www.ijc.com 1:38.

Hansen JJ, Nielsen B, Krogsgaard-Larsen P, Brehm L, Nielsen EØ, Curtis DR (1989) Excitatory amino acid agonists. Enzymic resolution, X-ray structure, and enantioselective activities of $(R)$ - and $(S)$ bromohomoibotenic acid. J Med Chem 32:2254-2260.

Hollmann M, Heinemann S (1994) Cloned glutamate receptors. Annu Rev Neurosci 17:31-108.

Jensen JB, Schousboe A, Pickering DS (1998) AMPA receptormediated excitotoxicity in neocortical neurons is developmentally regulated and dependent upon receptor desensitization. Neurochem Int 32:505-513.

Jensen JB, Schousboe A, Pickering DS (1999) Role of desensitization and subunit expression for kainate receptor-mediated neurotoxicity in murine neocortical cultures. J Neurosci Res 55:208-217.

Koike M, Tsukada S, Tsuzuki K, Kijima H, Ozawa S (2000) Regulation of kinetic properties of GluR2 AMPA receptor channels by alternative splicing. J Neurosci 20:2166-2174.

Krogsgaard-Larsen P, Honoré T, Hansen JJ, Curtis DR, Lodge D (1980) New class of glutamate agonist structurally related to ibotenic acid. Nature 284:64-66.

Krupp JJ, Westbrook GL (2000) An orphan glutamate channel points the way to the gates. Nature 3:301-302.

Lawrence CE, Altschul SF, Boguski MS, Liu JS, Neuwald AF, Wootton JC (1993) Detecting subtle sequence signals: a Gibbs sampling strategy for multiple alignment. Science 262:208-214.

Li F, Owens N, Verdoorn TA (1995) Functional effects of mutations in the putative agonist binding region of recombinant $\alpha$-amino-3-hydroxy5-methyl-4-isoxazole-propionic acid receptors. Mol Pharmacol 47:148-154.

Liman ER, Tytgat J, Hess P (1992) Subunit stoichiometry of a mammalian $\mathrm{K}^{+}$channel determined by construction of multimeric cDNAs. Neuron 9:861-871.

Lomeli H, Mosbacher J, Melcher T, Hoger T, Geiger JR, Kuner T, Monyer H, Higuchi M, Bach A, Seeburg PH (1994) Control of kinetic properties of AMPA receptor channels by nuclear RNA editing. Science 266:1709-1713.

Mano I, Teichberg VI (1998) A tetrameric subunit stoichiometry for a glutamate receptor-channel complex. NeuroReport 9:327-331.

Mano I, Lamed Y, Teichberg VI (1996) A venus flytrap mechanism for activation and desensitization of $\alpha$-amino-3-hydroxy-5-methyl-4isoxazolepropionic acid receptors. J Biol Chem 271:15299-15302.

Masella M, Flament J-P (2000) Influence of cooperativity on hydrogen bond networks. Molecular Simulation 24:131-156.

Mayer ML, Westbrook GL (1987) The physiology of excitatory amino acids in the vertebrate central nervous system. Prog Neurobiol 28:197-276.

Mohamadi F, Richards NGJ, Guida WC, Liskamp R, Lipton M, Caufield C, Chang G, Hendrickson T, Still WC (1990) MacroModel: an integrated software system for modeling organic and bioorganic molecules using molecular mechanics. J Comput Chem 111:440-467.

Mosbacher J, Schoepfer R, Monyer H, Burnashev N, Seeburg PH, Ruppersberg JP (1994) A molecular determinant for submillisecond desensitization in glutamate receptors. Science 266:1059-1062.

Nielsen B, Banke TG, Schousboe A, Pickering DS (1998) Pharmacology of $\left[{ }^{3} \mathrm{H}\right]$ AMPA binding to homomeric and heteromeric GluR $1_{o}$ and GluR3 receptors expressed in Sf9 insect cells. Eur J Pharmacol 360:227-238.

Paas Y (1998) The macro- and microarchitectures of the ligand-binding domain of glutamate receptors. Trends Neurosci 21:117-125.

Partin KM, Patneau DK, Mayer ML (1994) Cyclothiazide differentially modulates desensitization of $\alpha$-amino-3-hydroxy-5-methyl-4isoxazolepropionic acid receptor splice variants. Mol Pharmacol 46:129-138.

Partin KM, Fleck MW, Mayer ML (1996) AMPA receptor flip/flop mutants affecting deactivation, desensitization, and modulation by cyclothiazide, aniracetam, and thiocyanate. J Neurosci 16:6634-6647.

Rosenmund C, Stern-Bach Y, Stevens CF (1998) The tetrameric structure of a glutamate receptor channel. Science 280:1596-1599.

Schuler GD, Altschul SF, Lipman DJ (1991) A workbench for multiple alignment construction and analysis. Proteins 9:180-190.

Sommer B, Keinänen K, Verdoorn TA, Wisden W, Burnashev N, Herb A, Kohler M, Takagi T, Sakmann B, Seeburg PH (1990) Flip and flop: a cell-specific functional switch in glutamate-operated channels in the CNS. Science 249:1580-1585.

Stern-Bach Y, Bettler B, Hartley M, Sheppard PO, O'Hara PJ, Heinemann SF (1994) Agonist selectivity of glutamate receptors is specified by two domains structurally related to bacterial amino acid-binding proteins. Neuron 13:1345-1357.

Stern-Bach Y, Russo S, Neuman M, Rosenmund C (1998) A point mutation in the glutamate binding site blocks desensitization of AMPA receptors. Neuron 21:907-918.

Uchino S, Sakimura K, Nagahari K, Mishina M (1992) Mutations in a putative agonist binding region of the AMPA-selective glutamate receptor channel. FEBS Lett 24:253-257. 